\title{
BEEF CHUCK MUSCLE ISOLATION HAS NO EFFECT ON PREMIUM GROUND BEEF PROGRAMS
}

A Thesis presented to

The Faculty of the Graduate School

University of Missouri-Columbia

In Partial Fulfillment

Of the Requirements of the Degree

Master of Science

by

CLAIRYCE OHMAN

Dr. Bryon Wiegand, Thesis Supervisor

MAY, 2014 
The undersigned, appointed by the Dean of the Graduate School, have examined the thesis entitled

\section{BEEF CHUCK MUSCLE ISOLATION HAS NO EFFECT ON PREMIUM GROUND BEEF PROGRAMS}

presented by Claire Ohman

a candidate for the degree of Master of Science

and hereby certify that in their opinion it is worthy of acceptance.

\begin{tabular}{c}
\hline Dr. Bryon Wiegand \\
\hline Dr. Carol Lorenzen \\
\hline
\end{tabular}

Dr. Ingolf Gruen 


\section{ACKNOWLEDGEMENTS}

Firstly, I would like to acknowledge my advisor and committee members for their support and patience throughout my graduate experience. They provided me with the training and encouragement that I needed to conduct my research and write my thesis, and I am very appreciative of their assistance. I would also like to recognize the other graduate students, especially in the meat science group, for their time and expertise during data collection. Finally, I need to acknowledge my friends and family for their tremendous support, love and encouragement throughout my graduate school experience. 


\section{TABLE OF CONTENTS}

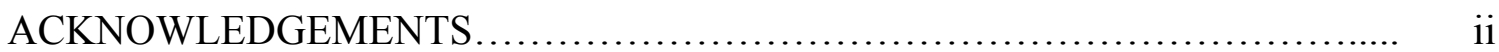

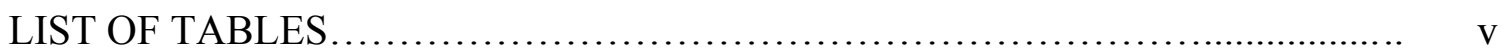

Chapter

1. LITERATURE REVIEW ............................................ 1

Consumer Purchasing Trends............................... 1

Lipid Oxidation.......................................... 2

Fatty Acid Profile Impacts Lipid Oxidation................ 3

Dietary Unsaturated Fat............................... 4

Lipid Oxidation Mechanism.......................... 4

Lipid Oxidation Initiators............................ 7

Factors that Influence Lipid Oxidation in Meat.............. 8

Antioxidants in Meat.......................................... 8

Myoglobin and Meat Color.................................. 10

The Myoglobin Molecule and Chemical States............. 10

The Conversion of Ferrous Myoglobin to Metmyoglobin..... 12

Oxidation of Myoglobin by Lipid Oxidation Products........ 12

Metmyoglobin Reducing Enzyme........................ 13

Consumer Acceptability of Color Change in Meat................ 14

Flavor Volatiles in Meat................................... 15

Warmed Over Flavor and Meat Flavor Deterioration.......... 16

Determination of Meat Color by Consumer Panel................. 18

Determination of Oxymyoglobin Concentration in Meat............ 18 
Determination of Meat Color by Minolta Chromameter............ 19

Determination of Meat Color by Reflectance Spectrophotometry.... 20

Determination of Lipid Oxidation by TBARS .................. 21

Determination of Lipid Oxidation by Peroxide Value.............. 22

Determination of Off-Odors by Sensory Panel................... 23

Identification and Quantification of Flavor Volatiles by SPME...... 23

Beef Muscle Profiling Project............................... 24

Response to Beef Muscle Profiling Project............... 25

Economic Impact...................................... 26

2. BEEF CHUCK MUSCLE ISOLATION HAS NO EFFECT ON PREMIUM

GROUND BEEF PROGRAMS ................................. 28

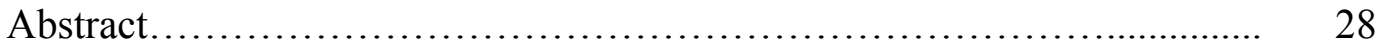

Introduction.................................................. 29

Materials and Methods.............................................. 30

Results and Discussion........................................ 36

Conclusions.................................................... 42

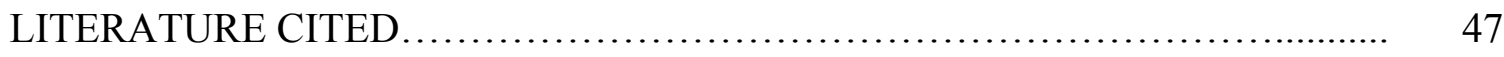

APPENDIX ........................................................ 57

Methods.................................................... 57

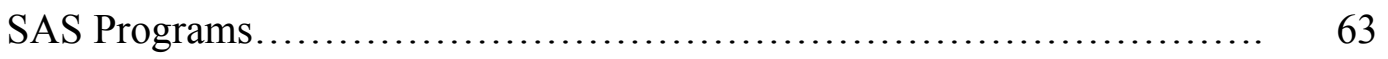




\section{LIST OF TABLES}

Table

1. Color analysis on raw patties on days $1,3,5$ and 7 after grinding..............43

2. Thiobarbituric Acid Reactive Substances (TBARS) analysis on day 2 and day 6

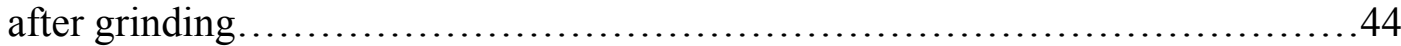

3. Sensory analysis on raw patties on days 1, 3, 5 and 7 and for 2,3 Octanedione concentration on cooked patties on days 1,3 , and $7 \ldots \ldots \ldots \ldots \ldots \ldots \ldots \ldots \ldots \ldots$

4. Correlations between concentration of oxymyoglobin, Minolta $a^{*}$ value and concentration of TBA..............................................46 


\section{CHAPTER I}

\section{LITERATURE REVIEW}

\section{CONSUMER PURCHASING TRENDS}

The inflation in food prices throughout time, coupled with a consistently turbulant national economy, has had a significant impact on the food puchasing decisions of many American families. People with higher incomes devote more of their paycheck to the purchase of meat products than do lower income consumers (Regmi, 2001). As people improve their economic status, they diversify their diets and begin to demand higher quality and more convenient products (Regmi, 2001). In addition to income, other factors contribute to the type and quantity of meat that consumers purchase, including preference, leisure time available to prepare food, and, most importantly, relative prices of foods (Regmi, 2001).

Sixty-one percent of Americans claim to be sensitive to the recent increase in food prices, and that the high cost has caused them to change their puchasing patterns (McCarty, 2011). Consumers are cutting expenditures where possible, and beef is often on the "chopping block". In 2011, 25.6 billion pounds of beef was consumed in the United States (USDA ERS, 2012), with a per capita intake of 57.4 lbs (USDA ERS, 2012); this is a $9 \%$ decline from $62.9 \mathrm{lb}$ in 2001 and a $21 \%$ decline from the $72.9 \mathrm{lb}$ per capita intake in 1981 (USDA, 2010). Many price sensitive consumers are "trading out", or substituting other foods, like poultry, completely in place of higher priced beef products (McCarty, 2011). The improved efficiency in the poultry industry makes poultry 
relatively a low-priced option when compared to beef (Chalfant, et al., 1988). Customers may also choose chicken due the desire to consume less saturated fat and cholesterol (Moschini and Meilke, 1989). Other customers are "trading down", or opting for lower-

priced foods; for example, choosing ground beef in place of whole muscle cuts (McCarty, 2011).

Ground beef is the most commonly purchased form of beef in the United States, due to both its relatively low price and variety of uses. Approximately $42 \%$ of beef is consumed as ground beef (Davis and Lin, 2005) and approximately $75 \%$ of American consumers eat ground beef at home during a 7-day period (Taylor, et al., 2007). Fourteen percent of linear footspace in self service retail meat cases is devoted to ground beef, up from $12 \%$ in 2008 . Meanwhile, whole muscle beef cuts command a smaller portion of retail cases, with $28 \%$ of footspace in 2008 , down from $30 \%$ in 2004 (Meat Retail Case Study, 2010). The price of ground beef has increased in comparison to whole muscle beef cuts, accordingly. In May, 2011, the price of steak had increased by $6.3 \%$ and ground beef by $13.6 \%$ in comparison to May 2010 (McCarty, 2011). Due to the increase in demand and price of ground beef, increased research in ground beef is also necessary to ensure a quality product to consumers.

\section{LIPID OXIDATION}

Lipid oxidation is the major, non-microbial cause of quality deterioration in ground beef. Lipid oxidation that occurs in the membrane and can result in a decrease in fluidity, impair membrane function and deactivate receptors and enzymes within the membrane (Baron and Anderson, 2002). Lipid oxidation can also lead to the development 
of off odors and flavors, as well as changes in color and texture, which can all lead to consumer rejection and shortened shelf life (Erickson, 2002). Furthermore, lipid oxidation results in the degradation of polyunsaturated fatty acids (Morrissey, et al., 1994) and can reduce the nutritional value of lipids (Ladikos and Lougovois, 1990) because vitamins, can act as antioxidants and are depleted during the process of lipid oxidation (Gordon, 2001). Although lipid oxidation in meat results in many negative consequences, it also contributes to the development of desirable cooked meat flavors (Farmer, 1994).

\section{Fatty Acid Profile Impacts Lipid Oxidation}

Lipids in animals are, for the most part, quite saturated. The phospholipid portion of intramuscular lipids, however, is considerably more unsaturated, and is a substrate for much of the oxidative reactions that occur in meat (Lillard, 1987). In beef Longissamus dorsi (LD), $44.4 \%$ of fatty acids are polyunsaturated, while only $3.5 \%$ of triglycerides are polyunsaturated (Hood, et al., 1971). In poultry, $41.4 \%$ and $43.5 \%$ polyunsaturated phospholipids are found in the breast and leg, respectively (Pikul, et al., 1984), similar to the degree of unsaturation of phospholipids in beef LD muscle. In this study, thiobarbituric acid reactive substances (TBARS) was conducted on fat collected from various parts of the chicken and showed that $90 \%$ of lipid oxidation resulted from the phospholipid portion of the lipid (Pikul, et al., 1984). This indicates that low-fat meats are still highly susceptible to lipid oxidation because the fat that was removed is predominantly triglycerides. The amount of phospholipids present in cell membranes, which are more prone to oxidation, remained relatively stable (Monahan, 2000). 


\section{Dietary Unsaturated Fats}

Differences in diet can significantly alter the fatty acid composition in animals, with the effect of dried distiller's grains with solubles (DDGS) playing a significant role in the industry today. With the increased demand for ethanol and the resulting expansion of the biofuels industry, the use of ethanol co-products in livestock rations has become common practice. The inclusion of distillers grains at 30\% in steer rations results in improved average daily gain and efficiency of gain, and tended to be increase hot carcass weight, fat thickness and yield grade (Al-Suwaiegh, et al., 2002), making DDGS attractive to beef farmers. However, the effect of DDGS on meat quality can be detrimental. The inclusion of DDGS compared to wet distiller's grains resulted in increased levels of linoleic acid (C18:2n-6), a polyunsaturated fatty acid, which contributed to an increase in lipid oxidation (Gill, et al., 2008). Additionally, DDGS included at $20 \%$ resulted in more total polyunsaturated fatty acids in the Longissamus dorsi when compared to the control (dry-rolled corn and soybean meal) diet (Koger, et al., 2010). The most prevalent phospholipid that contributes to cooked meat rancidity is phosphatidyl ethanolamine (Keller, and Kinsella, 1973).

\section{Lipid Oxidation Mechanism}

Oxidative rancidity can result from several different pathways, including hydrolytic, photo-oxidative and enzymatic, but the most important mechanism is by way of oxidation (Shahidi and Pegg, 2012), because it leads to the deterioration of foods containing unsaturated lipids. Oxidative rancidity occurs due to the reaction of unsaturated fatty acids, which are present in both phospholipids and triacylglycerols, with 
oxygen in a free radical chain mechanism (Gray, 1978). Initiation occurs when a hydrogen atom is abstracted from the unsaturated fatty acid chain (LH), creating a lipidfree radical $\left(\mathrm{L}^{*}\right)$. The hydrogen radical can be lost in the presence of several catalysts, including trace metals, heat, light (Frankel, 1984) or by a hydroxy radical $\left(\mathrm{HO}^{*}\right)$ or perferryl ion $\left(\mathrm{Fe}^{2+} \mathrm{O}_{2}\right)$ (Love, 1987). The lipid-free radical is attacked by diatomic oxygen, resulting in the production of a lipid peroxy radical (LOO*) in the propagation step (Frankel, 1984). The propagation step will continue, with radicals abstracting hydrogens from other unsaturated lipids, until two radicals react. Peroxy radicals (in addition to other primary lipid oxidation products) can abstract a hydrogen radical from another unsaturated fatty acid to continue the reaction into the termination step to produce hydroperoxide (LOOH) (Pearson, et al., 1977), or antioxidants can react with the LOO* to form stable radicals that are unable to react (Frankel, 1984), therefore halting lipid oxidation. If an antioxidant is not present, hemolytic cleavage of hydroperoxide often occurs, forming alkoxy radicals $\left(\mathrm{LO}^{*}\right)$, which can reenter the propagation phase (Frankel, 1984). Due to the rapid and uncontrolled nature of the lipid oxidation chain reaction mechanism, the steps are variable in sequence. The initiation, propagation and termination steps may occur as follows (Frankel, 1984):

$\begin{array}{llll}\text { Initiation: } & \mathrm{LH}+\text { Initiator } & \rightarrow & \mathrm{L}^{*} \\ \text { Propagation: } & \mathrm{L}^{*}+\mathrm{O}_{2} & \rightarrow & \mathrm{LOO}^{*} \\ & \mathrm{LOO}^{*}+\mathrm{LH} & \rightarrow & \mathrm{LOOH}+\mathrm{L}^{*} \\ \text { Termination: } & \mathrm{LOO}^{*}+\mathrm{H}^{*} & \rightarrow & \mathrm{LOOH} \\ & \mathrm{L}^{*}+\mathrm{L}^{*} & \rightarrow & \mathrm{LL}\end{array}$

The propagation step continues until two radicals react to form a product that is incapable of initiating or propagating (Monahan, 2000) in the termination step. Hydroperoxides $(\mathrm{LOOH})$ are colorless, tasteless and odorless molecules (Paquette, et al., 1985) that are 
often further broken down into compounds in the termination step that, even at concentrations below 1ppm, can result in altered flavor and odor profiles (Frankel, 1984). Flavors and aromas can change as a result of the accumulation of secondary volatiles, including aldehydes, ketones and epoxides (Ladikos and Lougovois, 1990). Lipid oxidation products include ketones, epoxides, and most importantly, aldehydes; namely, n-alkanal, trans-2-alkenal, 4-hydroxy-trans-2-alkanal, and malonaldehyde (Esterbauer et al., 1991). The products of aldehyde breakdown have a low threshold for off-odors, and therefore play a major role in the accumulation of undesirable odors in cooked meats (Shahidi and Pegg, 1994). These secondary products of lipid oxidation can result in acceleration of myoglobin oxidation (Faustman, et al., 1999). In order to retard the oxidation of lipids, several actions can be taken, including the prevention of oxygen exposure by vacuum, storing meat in lower temperatures, as well as the inclusion of antioxidants (Pokorny, 2001).

The rate of lipid oxidation is highest in an environment of low oxygen partial pressure (Renerre, 2000). Grinding meat can increase oxidation by disrupting the cell membrane and increasing the exposure of the lipids to catalysts (Erickson, 2002); it also increases surface area and mixes in oxygen (Gray, 1996). Different muscles in the chuck have variable susceptibilities to autoxidation. For example, the Infraspinatus is more prone to autoxidation than both the Supraspinatus and Serratus ventralis, as indicated by TBARS (McKenna, et al., 2005). 


\section{Lipid Oxidation Initiators}

Heme proteins were first found to be lipid oxidation initiators by Younathan and Watts (1960). As ferrous myoglobin is oxidized to metmyoglobin, a superoxide anion $\left(\mathrm{O}_{2-}{ }^{*}\right)$ is also formed, which is rapidly converted to hydrogen peroxide by dismutation and protonation (Monohan, 2000). The hydrogen peroxide can react with metmyoglobin, forming a pro-oxidant ferryl myoglobin state (Baron and Anderson, 2002). This product is a powerful catalyst of lipid oxidation (Faustman, et al., 2010). Myoglobin (heme-iron) and non-heme iron can both serve as pro-oxidants, although heme iron is the most important promoter of lipid oxidation (Rhee, 1987). Metals with two or more valences can also catalyze lipid oxidation by promoting hydroperoxide breakdown (Cross, et al., 1987). Iron, copper, cobalt and manganese are examples of metals with oxidation potential; iron, however, has the highest concentration in muscle (Love, 1987). For example, beef Longissimus dorsi has concentrations of $17.2 \mathrm{ppm}$ iron, $0.102 \mathrm{ppm}$ cobalt and 0.298 ppm manganese (Nour, et al., 1983).

Higher levels of iron can lead to increased rates of lipid oxidation (Faustman, et al., 1992). This contributes to increased lipid oxidation, catalyzed by heme iron. The catalytic ability of iron is increased significantly during cooking, as the iron becomes more available because of the denaturation of the protein moiety (St. Angelo, 1987). Additionally, non-heme iron has been found to act as a catalyst in accelerating lipid oxidation in cooked meats (Love, 1974). The physical disruption of cells and cell membranes by grinding can also increase lipid oxidation, and therefore, the incidence of off-odors (St. Angelo, 1987). Metal chelators, like phosphates and citrate, can bind metals and prevent or retard lipid oxidation (AMSA, 2012). 


\section{Factors that Influence Lipid Oxidation in Meat}

The rate of lipid oxidation can be decreased and increased by a variety of extrinsic factors. Environmental conditions, including oxygen concentration, temperature and light, impact meat significantly in terms of lipid oxidation. Lipid oxidation increases as temperature increases; therefore, refrigeration and freezing are effective in slowing lipid oxidation in comparison to ambient temperature (Monahan, 2000). In addition, temperature abuse during processing can be detrimental to meat in terms of both lipid and microbial deterioration, even if sufficient refrigeration occurs after processing (Mielche, 1995). Additionally, during meat preparation and processing, non-meat ingredients are added to the system. Many of these non-meat ingredients are pro-oxidant in nature, most notably sodium chloride (table salt). This lipid oxidation promoter likely increases lipid oxidation by releasing iron from the heme proteins, therefore allowing them to initiate lipid oxidation (Kanner, et al., 1991). Alternatively, phosphates are commonly added to processed meat products to improve water-binding capacity, but they are also effective in inhibition of lipid oxidation through metal chelation (Tims and Watts, 1958).

\section{ANTIOXIDANTS IN MEAT}

Oxidation can be prevented by including an antioxidant in the system. Antioxidants donate hydrogen atoms to free radicals, therefore making them unreactive and stopping the lipid oxidation chain reaction (Monahan, 2000). Many endogenous antioxidants exist, including both enzymatic antioxidants, including catalase, glutathione peroxidase and superoxide dismustase, which are denatured and deactivated during the cooking process, as well as non-enzymatic antioxidants, which are still active after 
cooking (Monahan, 2000). Non-enzymatic antioxidants of importance include lipidsoluble tocopherols and tocotrienols, as well as $\beta$ carotene and histidine containing dipeptides (Chan, et al., 1994).

Alpha-tocopherol is a powerful, endogenous and fat-soluble antioxidant that resides in skeletal muscle, with concentrations in beef top round of $3.4 \mathrm{mg} / \mathrm{kg}$ (Decker, et al., 2000). Concentrations of $\alpha$-tocopherol can be increased through dietary supplementation in beef cattle in the form of vitamin E. Vitamin E supplementation increased $\alpha$-tocopherol concentrations and delayed both lipid and oxymyoglobin oxidation in raw ground beef (Faustman, et al., 1989). Pasture-fed cattle often have higher concentrations of both $\alpha$-tocopherol and $\beta$-carotene compared to grain-fed cattle; these antioxidants delayed pigment and lipid oxidation, resulting in enhanced color retention, which was quantified by a* value (Insani, et al., 2008). With a high concentration of $\alpha$-tocopherol, metmyoglobin was less able to promote oxidation, resulting in lower TBARS (Lynch and Faustman, 2000). Another group tested the effect of treating the Longissamus lumborum with mineral oil containing D- $\alpha$-tocopherol to determine whether oxidation would be further prevented with exogenous antioxidants. They found that $\alpha$-tocopherol from the diet was much more effective in retarding lipid oxidation than exogenous $\alpha$-tocopherol (Mitsumoto, 1993).

Although endogenous antioxidants do exist in beef, lipid oxidation is not reduced enough to meet the needs of the meat industry (Decker and Mei, 1996); therefore, the addition of antioxidants is often used to slow lipid oxidation in processed meat products. BHA (butylated hydroxy anisole), BHT (butylated hydroxy toluene), spice extracts and vitamin $\mathrm{E}$ are often included in processed meat products because of their usefulness in the 
retardation or inhibition of metmyoglobin formation (AMSA, 2012).

\section{MYOGLOBIN AND MEAT COLOR}

Myoglobin is a sarcoplasmic, heme protein that is responsible for the majority of color in meat. Myoglobin content in meat depends on several factors, including animal age, sex and diet. Typical iron content in beef is $2-5 \mathrm{mg} / \mathrm{g}$ in beef (Livingston, and Brown, 1981), with more myoglobin accumulation in older animals. In the living animal, myoglobin binds oxygen and delivers it to the mitochondria (Wittenberg and Wittenberg, 2003). In a well-bled carcass; however, myoglobin provides $90-95 \%$ of the iron present in meat (Renerre, 2000). The blood pigment hemoglobin also provides color, contributing to $20-30 \%$ of the total pigment present (Fox, 1966). Cytochromes are essential for electron transport for respiration in living animals and also contribute to meat color, but at a much lower level (Renerre, 2000).

\section{The Myoglobin Molecule and its Chemical States}

Myoglobin has $8 \alpha$-helices and contains a protein moiety and a prosthetic group in its hydrophobic pocket, which is responsible for stabilizing the molecule and binding oxygen. Myoglobin also has a centrally located iron atom, which can form six bonds; four bind pyrrole groups and one with proximal histadine. The $6^{\text {th }}$ position bond can reversibly bind a ligand (Mancini and Hunt, 2005). The iron atom can exist in either an

oxidized $\left(\mathrm{Fe}^{3+}\right)$ or reduced $\left(\mathrm{Fe}^{2+}\right)$ form (Cornforth and Jayasingh, 2004). 


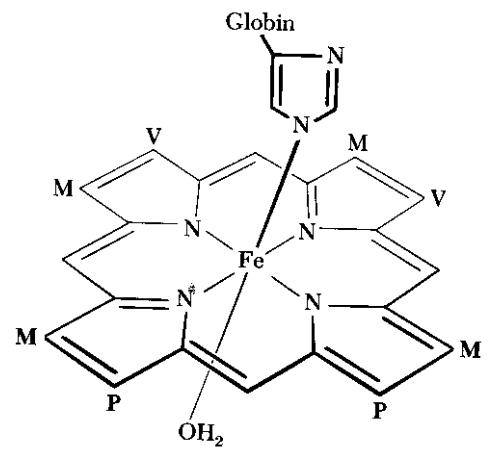

Figure 2. Ferric $\left(\mathrm{Fe}^{3+}\right)$ myoglobin structure. Photo courtesty of the Graduate School of Pharmaceutical Sciences, Chiba University.

The presence of a ligand at the sixth position and the charge of the iron determine the form of the myoglobin and the resulting color of the meat (Mancini and Hunt, 2005). Three major chemical forms of myoglobin are responsible for meat color, including two in the ferrous $\left(\mathrm{Fe}^{2+}\right)$ state, deoxymyoglobin and oxymyoglobin, and one in the ferric $\left(\mathrm{Fe}^{3+}\right)$ state, metmyoglobin. The $6^{\text {th }}$ position on the iron atom can bind diatomic oxygen (oxymyoglobin), water (metmyoglobin) or can remain unbound (deoxymyoglobin) (AMSA, 2012). Deoxymyoglobin is dark purple, oxymyoglobin is very bright red and metmyoglobin is characterized by a brown hue. Deoxymyoglobin is converted to oxymyoglobin as it is exposed to oxygen; the heme iron reversibly binds that oxygen in a process called blooming (Renerre, 2000). As oxygen becomes depleted through various cell processes or by vacuum, oxymyoglobin is converted into deoxymyoglobin (AMSA, 2012). Regardless of the chemical state of myoglobin (ferrous or ferric) state in fresh meat, upon cooking, the myoglobin is oxidized and denatured, forming a hemichrome, which exhibits a tan color (Claus, 2007). 


\section{Conversion of Ferrous Myoglobin to Metmyoglobin}

Oxidation of the iron within the heme group in any of the two ferrous $\left(\mathrm{Fe}^{2+}\right)$ forms results in the production of metmyoglobin (Mancini and Hunt, 2005). Although oxidation of oxymyoglobin to metmyoglobin may occur, the oxidation of deoxymyoglobin is more thermodynamically feasible (AMSA, 2012). Oxidation occurs as the iron is reduced to $\mathrm{Fe}^{3+}$ and binds a water molecule (Faustman, et al., 2010). A layer of metmyoglobin forms between the oxymyoglobin and deoxymyoglobin layers, which can significantly discolor the surface of meat (AMSA, 2012). As the metmyoglobin becomes thicker, the oxymyoglobin layer becomes thinner, resulting in the appearance of meat discoloration (Kropf, 2008). The rate of metmyoglobin accumulation is dependent on many factors, including $\mathrm{pH}$, muscle type, sex, and live animal diet as well as environmental factors, which include temperature, oxygen availability, lighting and storage of meat (Renerre, 2000). The rate of ferrous myoglobin oxidation increases as $\mathrm{pH}$ decreases (Faustman, 1989). Ferrous myoglobin to metmyoglobin conversion varies dramatically between muscles. For example, the Infraspinatus and Supraspinatus accumulate metmyoglobin at a much faster rate in comparison to the Longissamus lumborum and the Longissamus thoracis, as determined by reflectance spectroscopy (McKenna, et al. 2005).

\section{Oxidation of Myoglobin by Lipid Oxidation Products}

The interrelatedness of lipid oxidation and myoglobin oxidation is well documented, although the pathway that describes the oxidation of myoglobin by lipid oxidation is not well understood. The concentration of oxymyoglobin, as well as L* and 
$\mathrm{a}^{*}$ objective color values is strongly correlated with lipid oxidation, quantified in TBARS (Zakrys, et al., 2008). Additionally, antioxidant inclusion in meat processing retards both lipid and myoglobin oxidation, further proving the connection between the two mechanisms (Decker, et al., 2000). Free radicals produced during lipid oxidation can lead to the damage of myoglobin and hemoglobin, resulting in color loss in meat (Haurowitz, et al., 1941). Additionally, $\alpha \beta$-unsaturated aldehydes (nonenals and pentanals) are highly pro-oxidative secondary products of lipid oxidation. They significantly accelerate the conversion of ferrous myoglobin to metmyoglobin in muscle (Lynch and Faustman, 2000). These aldehydes can also decrease myoglobin stability by covalently attaching to the oxymyoglobin molecule (Lynch and Faustman, 2000). In order to slow both lipid oxidation and pigment oxidation, the formation of metmyoglobin must be prevented so that lipid oxidation catalysts are not synthesized, and lipid oxidation must be prevented so that the oxidation intermediates cannot damage heme pigments (Greene, 1969).

\section{Metmyoglobin Reducing Enzyme}

Meat purchasing decisions are influenced by color more than any other quality factor (Smith, et al., 2000), and brown, discolored meat is highly discriminated against by consumers (Hood and Riordan, 1973). The formation of metmyoglobin results in meat discoloration and a deviation from the bright red color that consumers prefer in their meat. If formed, metmyoglobin can be reduced by an enzyme called NADH-cytochrome $\mathrm{b}_{5}$ reductase (Arihara, et al., 1989), more commonly known as metmyoglobin reductase. Metmyoglobin reductase may extend the shelf life of fresh meat (Renerre, 2000). This enzyme can reduce metmyoglobin to myoglobin, but is NADH-dependent and must be in 
the presence of either ferrocyanide or cytochrome $b_{5}$ (Arihara, et al., 1989). Reddy and Carpenter (1991) showed that muscles with higher metmyoglobin reducing activities are also often characterized as the most color stable. The importance of this enzyme in meat color stability is a topic of debate. According to Ledward, metmyoglobin reductase is of high importance in determining meat color stability (1985). O'Keeffe and Hood, conversely, have shown that meat color stability is more dependent on oxygen consumption rate, which is determines the ability of oxygen to penetrate the exposed muscle. Other researchers have concluded that both of these pathways are of importance to color stability, and that low color stability muscles have a low proportion of reducing ability in comparison to the oxygen consumption rate (McKenna, et al., 2005).

\section{CONSUMER ACCEPTABILITY OF COLOR CHANGE IN MEAT}

Consumer behavior and purchasing patterns are determined by their needs and the food available to meet those needs (Troy, 2010). Additionally, consumers purchase based on "quality cues", which can include both intrinsic factors like color and visible fat, as well as extrinsic factors, including price, brand and product origin (Troy, 2010). Consumers use the intrinsic cue of brown color development as an indicator of quality deterioration in fresh meats. Meat purchasing decisions are influenced by color more than any other quality factor because consumers use discoloration as an indicator of freshness and wholesomeness (Smith, et al., 2000). Additionally, consumers prefer a cherry-red lean color, and deviations from this can also result in discrimination (Liu, et al. 1995). Perception is based on experiences, in addition to the visual, flavor and odor attributes (Troy, 2010). Since consumers cannot assess odor and flavor on packaged meat, color 
analysis becomes more important in their purchasing decisions (Faustman and Cassens, 1990). At the point of sale, meat color is the most important factor in determining quality (Troy, 2010). Consumers prefer bright red (oxymyoglobin) patties to purple (deoxymyoglobin) and preferred purple to brown (metmyoglobin), but this preference and likelihood to purchase did not impact the resulting taste satisfaction (Carpenter, 2001). Green, et al. found that meat discoloration results in consumer rejection when metmyoglobin concentration reaches 30-40\% (1971). Hood, et al. showed that consumers begin to discriminate at an even lower concentration of metmyoglobin (1973). When discolored meat with $20 \%$ surface metmyoglobin is sold alongside bright red beef, the discolored beef is highly discriminated against; the sales ratio of the discolored beef in comparison to the bright red beef is 1:2 (Hood, et al., 1973), indicating significant discrimination. Discolored meat, therefore, often must be discounted or ground in order to be saleable (Liu, et al., 1995). Nearly $15 \%$ of retail beef is discounted in price due to surface discoloration, leading to annual meat industry revenue losses totaling approximately $\$ 1$ billion (Smith, et al., 2000).

\section{FLAVOR VOLATILES IN MEAT}

Off-flavor is used to describe unpleasant odors and tastes resulting from the deterioration of foods, with severe deterioration resulting in rancidity (Pegg and Shahidi, 2012). More than 1,000 volatile compounds, which contribute to odor and flavor, have been identified in meat (Bailey, 1989), and certainly many more are still undiscovered. The ability to detect and identify the accumulation of meat odors and off-odors varies 
from person to person. Over 1,000 olfactory receptor genes exist in humans that enable us to detect these odors, sometimes at concentrations as low as $0.01 \mathrm{ppb}$ (Baigrie, 2003).

The cooking process involves significant changes within meat, with many reactions occurring in the lipid portion, specifically fatty acids, triglycerides and phospholipids, which are degraded oxidatively and hydrolytically (Bailey, 1989). The "brothy" or "meaty" flavor associated with cooked meat is the result of many reactions between amino acids, peptides, glycopeptides, proteins, sugars, sugar phosphates, nucleotides, nucleosides, purines and pyrimidines in the Malliard reaction (Bailey, 1989), which also results in the brown, cooked color of meat. The lipid components, after cooking, are responsible for the flavors that make beef smell and taste different from other red meats (Hornstein and Crowe, 1960). The interaction between the lipid and water-soluble fractions of meat produce many intermediate products that contribute to the flavor of beef (Bailey, 1989). The accumulation of off-odors can be the result of microbial contamination as well as oxidative rancidity (Shahidi and Pegg, 2012), with the latter being the main contributor to Warmed-Over Flavor (WOF). Freshly cooked beef contains many flavor volatiles, $80 \%$ of which are high molecular weight aldehydes (Bailey, 1980). Products of aldehyde breakdown are of interest because of their contribution to off-odors; most notably, WOF.

\section{Warmed Over Flavor (WOF) and Meat Flavor Deterioration (MFD)}

WOF is generally characterized as an old, stale, or rancid odor and is often compared to the smell of paint or wet cardboard, and was first characterized by Tims and Watts (1958). The development of WOF is the result of lipid oxidation that occurs in pre- 
cooked and refrigerated meat within 48 hours of cooking (Cross, et al, 1987), and can lead to a significant deterioration in flavor (Love, 1987). Other researchers have found that protein degradation is partly responsible for this deterioration in meat flavor described by Love in 1987. For this reason, Meat Flavor Deterioration (MFD) is also used to describe this loss in meat quality (Shahidi and Pegg, 1994).

WOF is an issue for restaurants and airlines that serve reheated, pre-cooked meats, and it is also responsible for consumer dissatisfaction with leftovers (St. Angelo, 1987). Additionally, the increase in demand for ready-to-eat, convenient meat entrees has made the prevention or retardation of WOF development a topic of interest for meat scientists (Cross, et al., 1987). The susceptibility of meat to WOF, caused by lipid oxidation, is dependent on many factors, including the species, the diet fed, the type of fat utilized (subcutaneous, body cavity, intramuscular, etc.) and meat handling, both pre- and post-processing (Cross, et al., 1987). Antioxidants are often utilized in the retardation of WOF (St. Angelo, 1987), although endogenous, antioxidant enzymes are denatured and disabled during the cooking process (Monahan, 2000). WOF is highly correlated with the concentrations of several lipid oxidation secondary products, including pentanal, hexanal and 2,3-octanedione in chicken, turkey and beef (St. Angelo, 1987).

Off-odors become apparent at TBA values of 1-2 mg TBA/kg in beef (Zipser and Watts, 1962). Although malonaldehyde does not contribute to WOF, TBARS and hexanal concentrations are highly correlated $\left(\mathrm{R}^{2}=0.804\right)$ in pork (Fernando et al., 2003) and $\left(\mathrm{R}^{2}=0.994\right)$ in turkey (Brunton, et al., 2000). In addition to the development of off-odors in pre-cooked and reheated meat, WOF can also occur at a similar rate in raw meat when muscles are ground. Cell membranes are disrupted during grinding and heme iron, which 
is a catalyst for lipid oxidation, becomes more available (Judge and Aberle, 1980) and this rancid WOF is not destroyed by cooking (Green 1969).

\section{DETERMINATION OF MEAT COLOR BY CONSUMER PANEL}

Sensory panels are useful in tracking visible changes in lean color and percent discoloration. Panels are comprised of either 'trained' or 'untrained' panelists. A 'trained' panel is usually exposed to materials before the evaluations that help the panelist select the most representative color or percent discoloration for a particular sample (Rhee, 1997). Panelist color and percent discoloration evaluation should be analyzed since consumers make the 'purchase' or 'no purchase' decision, often based solely on appearance (Faustman and Cassens, 1990). In addition to color and percent discoloration by sensory panel, asking the panelists to decide to 'purchase or 'not purchase' based on appearance is also useful in determining consumer acceptance.

\section{DETERMINATION OF OXYMYOGLOBIN IN MEAT}

Oxymyoglobin and deoxymyoglobin content in meat is converted to metmyoglobin over time, as the heme iron is oxidized from $\mathrm{Fe}^{2+}$ to $\mathrm{Fe}^{3+}$. This process results in an increase in discoloration, which can lead to customer discrimination (Liu, et al. 1995). The quantification of oxymyoglobin concentration over time is important in determining the rate of discoloration, and rate of discoloration can be used to compare ground beef blends, for example. A rate of oxymyoglobin deterioration that is less severe means that a particular blend or certain environmental conditions result in longer color retention, and therefore, less consumer discrimination. Oxymyoglobin content 
determination quantifies all non-oxidized $\left(\mathrm{Fe}^{2+}\right)$ myoglobin; i.e., everything except metmyoglobin $\left(\mathrm{Fe}^{3+}\right)$ (Krzywiki, 1982). Therefore, all $\mathrm{Fe}^{2+}$ forms, namely oxymyoglobin and deoxymyoglobin, are pushed to the oxymyoglobin state. A phosphate buffer (pH 6.8) is added to homogenized meat to prevent additional oxidation to the metmyoglobin state. Absorbance is read on a spectrophotometer at $418 \mathrm{~nm}$, which is the maximum absorbance of oxymyoglobin.

\section{DETERMINATION OF MEAT COLOR BY MINOLTA CHROMAMETER}

Objective meat color measurement is important in determining rates of discoloration and can be compared to consumer color analysis and pigment concentrations. Color is described in three ways, by lightness (known as value), saturation (known as chroma) and hue. The Commission Internationale de l'Eclairage (CIE) introduced 'color space', which measures color in terms of $\mathrm{L}^{*}, \mathrm{a}^{*}$ and $\mathrm{b}^{*}$, or CIELAB (Berardesca, 1995). $\mathrm{L}^{*}$ measures darkness (-L*) to lightness $\left(+\mathrm{L}^{*}\right), \mathrm{a}^{*}$ measures greenness $\left(-a^{*}\right)$ to redness $\left(+a^{*}\right)$ and $b^{*}$ measures blueness $\left(-b^{*}\right)$ to yellowness $\left(+b^{*}\right)$. All three lines are continuous and perpendicular to each other, creating a color sphere that was inspired by the Munsell color space (Berardesca, 1995). A chromameter has photodiodes that contain red, blue and green sensitive cones in the central foveola, simulating the human eye. The chromameter shines light on the sample, and is reflected back into the instrument and sent through the photodiodes. The light is transformed into electrical signals when it reaches the sensors. The signals are calculated into color values for $\mathrm{L}^{*} \mathrm{a}^{*}$ and $\mathrm{b} *$ (Berardesca, 1995). These values can be compared across time, experimental unit, etc. to determine color, color retention, and rate of fading. 


\section{DETERMINATION OF MEAT COLOR BY REF. SPECTROPHOTOMETRY}

Consumer panels are useful in detecting visible changes in color and percent discoloration in meat, but if subtle changes need to be documented, more sensitive measurement devices should be utilized (Krzywicki, 1979). Reflectance spectrophotometry is a method for the quantitative determination of meat pigments. This method is often preferred to CIE determination because a direct relationship can be made between subjective consumer analysis and actual changes in the relative concentrations of meat pigments (Hood and Riordan, 1973). Reflectance spectrophotometry is determined by the reflectivity of the sample, and expressed as $\mathrm{K} / \mathrm{S}$, where $\mathrm{K}$ and $\mathrm{S}$ are constants for absorption and scattering coefficients, respectively (Kubelka, 1948). Reflectance $\left(\mathrm{R}_{\infty}\right)$ is measured at two specific absorption points, the first at $525 \mathrm{~nm}$, which is isobestic (linearly related) for all three forms of myoglobin. The conversion of the absorbance at $525 \mathrm{~nm}$ to $\mathrm{K} / \mathrm{S}$ values determines total pigment present in the sample (Hood and Riordan, 1973). The second absorption is read at $572 \mathrm{~nm}$, which is isobestic for oxymyoglobin and reduced myoglobin. In order to determine the concentration of metmyoglobin, the ratio of $(\mathrm{K} / \mathrm{S})_{572}$ to $(\mathrm{K} / \mathrm{S})_{525} \mathrm{~nm}$ is calculated (Hood, 1973) using the following formula:

$$
\mathrm{K} / \mathrm{S}=\frac{\left(1-\mathrm{R}_{\infty}\right)^{2}}{2 \mathrm{R}_{\infty}}
$$

$\mathrm{K} / \mathrm{S}$ ratios are determined for both $0 \%$ and $100 \%$ metmyoglobin with the inclusion of a reducing agent, sodium hydrosulfite and an oxidizing agent, potassium ferricyanide, respectively. The two ratios are used to find a linear relationship, which can then be used to determine metmyoglobin concentrations between $0 \%$ and $100 \%$ metmyoglobin (Stewart, 1965). This method is preferred to chemical analysis of oxymyoglobin content because the sample is not destroyed during analysis, and therefore can be used to track 
metmyoglobin formation during days of storage. Consumers reject or downgrade ground beef for purchase when metmyoglobin content exceeds $40 \%$, as determined by reflectance spectrophotometry (Greene, et al., 1971), which would correspond to a change in $(\mathrm{K} / \mathrm{S})_{572} /(\mathrm{KS})_{525}$ of $1.20(\operatorname{Hood}, 1975)$.

\section{DETERMINATION OF LIPID OXIDATION IN MEAT BY TBARS}

The Thiobarbitruic Acid Reactive Substances (TBARS) test is one of the most common methods of lipid oxidation measurement. Malonaldehyde is a secondary product of lipid oxidation, and is produced as a result of polyunsaturated fatty acid breakdown (Shahidi and Zhong, 2005). Malonaldehyde is often selected for oxidative deterioration measurement because it can be detected early as oxidation occurs and because the test is very sensitive (Cesa, 2004). Malonaldehyde is heated with an acid solution and 2, 2thiobarbituric acid (TBA) molecules, which react in a condensation reaction to form a chromophore (Sinnhuber and $\mathrm{Yu}, 1977)$. TBA may also form a chemophore with an identical absorbtion maxiumum (Shahidi and Pegg, 1994) with other secondary products of lipid oxidation, in addition to malonaldehyde (Devasagayam, 2003). For this reason, this test is referred to as Thiobarbituric Acid Reactive Substances (TBARS), instead of TBA value (Shahidi and Pegg, 1994).

The amount of TBARS is determined by finding the concentration of the chemophore, which has an absorbance maximum of 532nm (Sinnhuber and $\mathrm{Yu}, 1977)$. A higher concentration of TBARS, and therefore a higher degree of lipid oxidation, will result in a darker pink hue (Shahidi, 2005). The resulting pale to bright pink solution is read at $532 \mathrm{~nm}$ on a spectrophotometer, and samples should be compared with a standard 
curve. The reaction of 2-thiobarbituric acid and malonaldehyde occurs as follows (Oxford Biomedical Research, 2012):
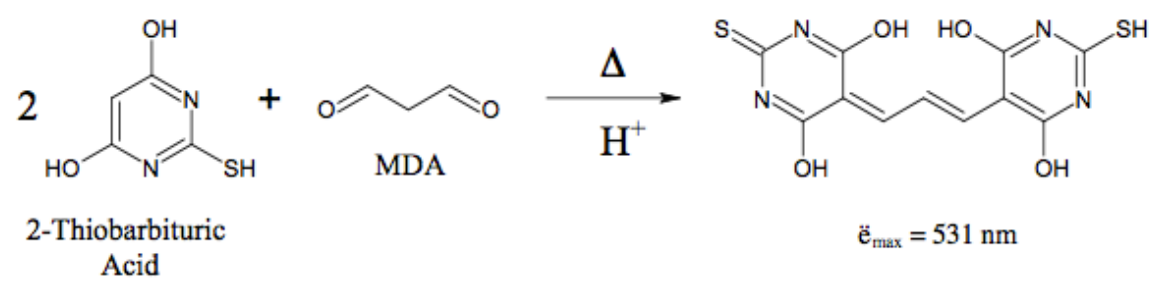

Figure 2. Chemical reaction between TBA and malonaldehyde. Figure courtesy of Oxford Biomedical Research.

\section{DETERMINATION OF LIPID OXIDATION IN MEAT BY PEROXIDE VALUE}

Peroxide value is a measurement of the total hydroperoxide present at the time of analysis. Lipid oxidation involves constant hydroperoxide formation as a primary product and its subsequent decomposition into secondary products (Shahidi, 2005); therefore, peroxide value is a good indicator of the onset of lipid oxidation. Three methods of peroxide determination are primarily used, the most often utilized procedure is the idometric procedure described by Lea (1952). Peroxides can be measured by their ability to liberate iodine from potassium iodide (KI). The sample to be analyzed is dissolved in a solvent and excess KI is added. The reaction occurs as follows:

$$
\mathrm{ROOH}+\mathrm{KI} \rightarrow \mathrm{ROH}+\mathrm{KOH}+\mathrm{I}_{2}
$$

Therefore, the amount of peroxides present can be determined by finding the amount of liberated $\mathrm{I}_{2}$ present. The solution is titrated with sodium thiosulfate until colorless. The sodium thiosulfate reacts with the $\mathrm{I}_{2}$ to form a colorless $\mathrm{I}^{-}$. A simple calculation using the amount of sodium thiosulfate that was titrated will determine the amount of liberated $\mathrm{I}_{2}$, 
and therefore, the amount of hydroperoxides present in the sample (McClements, 2003).

\section{DETERMINATION OF OFF-ODORS IN MEAT BY SENSORY PANEL}

Sensory panels are useful in describing and quantifying undesirable odors in raw and cooked meat. Panels are comprised of either 'trained' or 'untrained' panelists. A 'trained' panel is exposed to materials before the evaluations that help the panelist describe the specific odors that they are expected to encounter. Off-odor descriptors may include 'fruity', 'sour', 'putrid' (Rhee, 1997), or 'rancid' (Greene, 1969). Strawberry yogurt is often used to reinforce the 'fruity' off-odor and buttermilk is used for the 'sour' off odor, for example (Rhee, 1997). Quantification is generally described in terms of flavor intensity, and can be accomplished with a hedonic scale. In this case, panelists are asked to smell the sample and assign to it a value (generally $0-10$ ) that matches the its degree of intensity of that particular descriptor (Melton, et al., 1987). Odor intensity scale markers can be created with vials containing increasing concentrations of vanilla, $(0 \%$ vanilla $=0,100 \%$ vanilla $=10)($ Rhee, 1997). Off-odor determination is often conducted in the following manner: the meat sample is placed in a glass petri dish with a watch glass covering the dish to accumulate volatiles. Panelists lift the watch glass and sniff the sample to evaluate off-odors (Rhee, 1997). Panelists record the off-odor(s) that they identify and odor intensity on the hedonic scale.

\section{IDENTIFICATION AND QUANT. OF FLAVOR VOLS IN MEAT BY SPME}

The identification and quantification of flavor volatiles was accomplished with the solid-phase microextraction (SPME) analytical technique, which was developed by 
Arthur and Pawliszyn (1990). The analysis of volatiles in the headspace is important because consumers can detect those same volatiles while they eat; they stimulate olfactory sensors and are perceived as off-odors (Linforth and Taylor, 1993). Flavor volatiles are extracted from meat by converting them from the gaseous or liquid phase into an immobilized, solid phase for quantification (Steffen and Pawliszyn, 1996). The SPME device utilizes a fused silica fiber, which should be selected specifically for the volatiles of interest (Steffen and Pawliszyn, 1996). The SPME needle pierces the septum and the fiber is extended into the headspace above the sample. The flavor volatile analytes are absorbed and concentrated into the stationary phase within the fiber, and the fiber is subsequently placed into the injection port of the gas chromatograph (Kataoka, 2000). Desorption of the analyte and subsequent quantification occurs in the gas chromatograph (Kataoka, 2000). SPME is fast, inexpensive, solvent-free and easy to conduct, and is therefore widely utilized for volatile analysis (Yang and Peppard, 1994).

\section{BEEF MUSCLE PROFILING PROJECT}

The Cattle Fax organization found that beef ribs and loins increased 3-5\% in value and the wholesale value of chucks, rounds and trimmings decreased $25-26 \%$ in value during a five year period, from 1993-1998 (Von Seggern, et al., 2005). In response, the Cattle Fax organization concluded that research needed to be conducted on chucks and rounds to find a way to increase demand for those 'underutilized' cuts (Von Seggern, et al., 2005). In order to accomplish this, physical and chemical analyses were conducted on more than 5,000 muscles across 142 beef carcasses to create a database of muscle characteristics. Objective color, expressible moisture, proximate composition, emulsion 
capacity, $\mathrm{pH}$, total collagen content, total heme-iron concentration, and Warner-Bratzler shear force were conducted on each of 39 muscles located in the chuck and round. This information can help find the best use for each muscle, based on its characteristics (Redson, 2011) and can also help meat retailers make a more informed decision about muscle inclusion in value added products (Von Seggern, et al., 2005).

\section{Response to the Beef Muscle Profiling Project}

This new information has lead to the isolation of 13 new "Value Cuts" (Redson, 2011), and is partially responsible for the increase in carcass value by and estimated $\$ 50$ $\$ 70$ per head (Von Seggern, et al., 2005). These value cuts are single muscle cuts that fall between premium steaks and ground beef in both quality and price (Redson, 2011). These cuts include the Petite Tender, Petite Tender Medallions, Flat Iron and Ranch Steak sourced from the shoulder clod, the Western Griller Steak, Western Tip, Sirloin Tip Side Steak and the Sirloin Tip Center Steak from the round, and the Boneless Country-Style Beef Chuck Ribs, Sierra Cut, America's Beef Roast, Denver Cut and the Delmonico Steak from the chuck roll (Redson, 2011). A culinary team created recipes and optimal cooking conditions and consumer panels determined responses to recipes, names and taste (Redson, 2011). In response to an aggressive marketing campaign, 81 million pounds of the flat iron steaks, a value cut, were used in foodservice in 2010, in comparison to 21 million pounds of porterhouse steaks and 40 million pounds of T-bone steaks in the same year (Technomic, 2010). 39 million pounds of petite tenders and 26 million pounds of ranch steaks were also used in the foodservice industry in 2010 (Technomic, 2010). 


\section{Economic Impact}

The decline in the United States economy from 2008 through 2010 resulted in a change in consumer behavior and has had a significant impact on the beef industry. This economic uncertainty has caused consumers to be more price conscious; for this reason, many beef consumers are "trading down" from higher priced steaks and roasts to lower cost items, such as ground beef (McCarty, 2011). In August of 2013, the national, averaged price of ground beef was US $\$ 1.57$ per kilogram, while choice sirloin steak was US \$3.00 per kilogram (USDA-ERS, 2013). Although these prices vary by geographical location, this price spread has attracted consumers to ground beef and away from whole muscle steaks and roasts across the country. Due to this increase in demand for ground beef, the price of ground beef had increased by 13.6\% from May 2010 to May 2011 in comparison to steak, which had only increased by 6.3\% (McCarty, 2011).

In addition to the increase in demand for ground beef, the meat industry is currently working to increase the value of the chuck by developing new "value cuts" for individual sale and excluding them from the ground beef mix (Redson, 2011). In August of 2013, wholesale beef was worth US $\$ 1.34$ per kilogram, while retail beef was worth US $\$ 2.45$ per kilogram, yielding a wholesale to retail spread of US \$1.11 per pound (USDA, 2013). If the practice of isolating certain muscles from the chuck is adopted by meat processors, the price of beef in a retail setting would likely change, as will the wholesale/retail spread. According to Von Seggern et al., if half of the 5-year increase in price were to be assigned to the beef chuck, then beef carcasses will have gained an extra US \$50$\$ 70 /$ head in value, partially due to this initiative (2005). This increase in beef chuck value is impressive; however, several indirect consequences of this practice may exist. Firstly, 
the removal of muscles from the chuck for individual retail sale will reduce the total amount of ground beef available for retail sale. With the increase in demand for ground beef, this could result in a supply issue. Additionally, those muscles that have been selected for use as steaks have specific color and oxidative stabilities and functional characteristics (Von Seggern, et al., 2005). Meat processors may be concerned that removing these muscles may result in ground beef with less days of shelf life, and lead to customer rejection. Therefore, further research regarding the impact of removing certain muscles from ground chuck must be conducted to ensure a quality ground beef product to the consumer. 


\title{
CHAPTER 2
}

\section{BEEF CHUCK MUSCLE ISOLATION HAS NO EFFECTS ON PREMIUM GROUND BEEF PROGRAMS}

\begin{abstract}
This experiment evaluated whether isolating certain muscles from the chuck for retail sale and excluding them from the ground beef mix changes the number of days that ground chuck is acceptable to consumers. Chucks were harvested from twenty-four beef steers, and were allocated to either a traditional or an innovative method. Resulting ground beef patties were stored in retail simulation conditions for $7 \mathrm{~d}$ to determine color and oxidative stability. Raw patties were analyzed for thiobarbituric acid reactive substances (TBARS), oxymyoglobin concentration, objective color by Minolta colorimeter, and by a trained sensory panel for odor, color and percent discoloration. No differences $(P>0.05)$ were observed between traditional and innovative style patties for TBARS, sensory odor or color, or oxymyoglobin concentration. Minolta Chromameter readings revealed more substantial fading $(P<0.05)$ in traditional patties compared with the innovative style patties. This study demonstrated that removing certain muscles from the ground chuck mix does not result in any detrimental consequences in resulting ground chuck patties.
\end{abstract}




\section{INTRODUCTION}

From 1993 to 1998, the price of chucks and rounds dropped 25-26\%, prompting research to increase the value of these "underutilized" cuts (Von Seggern, et al., 2005). The success of the Beef Muscle Profiling Project led processors to isolate muscles from the chuck for individual sale and gain an approximate US $\$ 50$ to $\$ 70 /$ head in market value (Von Seggern et al., 2005). One of the consequences of this practice is the decrease in ground chuck available for premium grinds.

Ground beef is the largest percentage of all beef items consumed at home or sold into foodservice (Lundeen, 2011). Approximately 42\% of beef is consumed as ground beef (Davis and Lin, 2005). Fourteen percent of linear footspace in self service retail meat cases was devoted to ground beef in 2010, up from $12 \%$ in 2008 . Additionally, whole muscle beef cuts commanded $28 \%$ of footspace in 2010 , down from $30 \%$ in 2004 (Meat Retail Case Study, 2010). This increase in demand for ground beef was a result of the poor economic situation, which has caused many consumers to "trade down" from higher priced steaks and roasts to lower cost items such as ground beef (McCarty, 2011). Due to the change in consumer purchasing patterns, the price of ground beef has increased in comparison to whole muscle beef cuts. In May, 2011, the price of steak had increased by $6.3 \%$ and ground beef by $13.6 \%$ in comparison to May 2010 (McCarty, 2011).

In addition, differences exist in functional characteristics, such as color, hemeiron content and $\mathrm{pH}$, between the most popular chuck muscles being utilized as steaks (Von Seggern et al., 2005). Using muscles with different color stabilities in ground beef can dramatically affect shelf life as determined by discoloration and oxidation (Raines, et 
al., 2010). At the point of sale, meat color is the most important factor in determining quality (Troy, 2010); therefore, a change in the rate of discoloration can greatly impact consumer-purchasing decisions. Nearly $15 \%$ of retail beef is discounted in price before it can be sold due to surface discoloration, leading to annual revenue losses in the meat industry totaling approximately US $\$ 1$ billion (Smith, et al., 2000). Therefore, meat retailers are interested in the impact of excluding muscles on the days of viable shelf life of the resulting ground beef.

The objective of this study was to determine the impact of removing high value muscles from ground chuck on the overall odor and color stability of ground chuck at four different retail storage time periods.

\section{MATERIALS AND METHODS}

\section{Ground Beef Manufacture}

Twenty-four beef steers were slaughtered at the University of Missouri-Columbia in groups of six. Right chucks were assigned to a traditional method (TRA) and left chucks to an innovative method (INN). TRA included trim from the neck and shank, half of the clod (IMPS 114) and half of the chuck roll (IMPS 116A). INN included trim from the neck and shank, half of the clod heart (IMPS 114E), half of the chuck eye roll (IMPS 116D), and excluded the Infraspinatus (IMPS 114D), Supraspinatus (IMPS 116B), Teres major (IMPS 114F) and Serratus ventralis (IMPS 116G). During fabrication, muscle and ground beef weights were collected for use in economic analysis. Resulting ground beef patties were placed on Styrofoam ${ }^{\circledR}$ trays, overwrapped with polyvinyl chloride (PVC) 
and displayed under florescent lights at approximately $4{ }^{\circ} \mathrm{C}$ for up to 7 days following fabrication to determine color and oxidative stability.

Fat Determination

Fat percentage determination, using the CEM procedure (CEM SMART Trac system, Matthews, NC, USA), described in Dow et al. (2011) was conducted in triplicate. Briefly, $3.75-4.5 \mathrm{~g}$ of sample was dried in between two pads, wrapped in TRAC paper, and packed into the bottom of the CEM TRAC tube. Fat percentage was determined on a dry weight basis using nuclear magnetic resonance and converted to a wet weight basis.

\section{Determination of Lipid Oxidation}

Patties were pulled on days 2 and 6 after fabrication to determine the degree of lipid oxidation using the thiobarbituric acid reactive substances (TBARS) extraction method, described by Pegg (2001). Briefly, $5 \mathrm{~g}$ of ground meat, $2.5 \mathrm{~mL}$ antioxidant solution, $50 \mathrm{~mL}$ TCA reagent and $50 \mathrm{~mL}$ distilled water was homogenized. The slurry was filtered, and a $5 \mathrm{~mL}$ aliquot was pipetted into a $50 \mathrm{~mL}$ centrifuge tube. $5 \mathrm{~mL}$ thiobarbituric acid (TBA) reagent $(0.02 \mathrm{M}$ TBA in distilled water) was added to the solution and the tube was capped and vortexed for $3 \mathrm{sec}$. The tubes were placed in a boiling water bath for $35 \mathrm{~min}$, removed, and placed promptly in ice for $5 \mathrm{~min}$. The sample was transferred into a cuvette and absorbance was read at $532 \mathrm{~nm}$ using a spectrophotometer. A standard curve and malonaldehyde recovery were conducted and the following calculation was used to determine $\mathrm{mg}$ TBARS $/ \mathrm{kg}$ meat:

$$
\% \text { recovery of TBARS }=100 \times \mathrm{A}_{\mathrm{sp}} / \mathrm{A}_{\mathrm{tmp}}
$$


where $A_{s p}$ is the absorbance of the spiked food sample (corrected) and $A_{\text {tmp }}$ is the absorbance of the corresponding TMP dilution. The resulting percent recoveries are averaged and used in determining the TBA value.

To find TBA Value, K (constant) must be determined using the following calculation:

$$
\mathrm{K}=\left(\left((\mathrm{mol} \mathrm{MA} / 5 \mathrm{~mL}) / \mathrm{A}_{532}\right) \times(\mathrm{MA} \text { mol. weight }) \times(\mathrm{DF}) \times(106) \times(100 / \% \text { recovery })\right) / \mathrm{m}
$$

where $(\mathrm{mol} \mathrm{MA} / 5 \mathrm{~mL}) / \mathrm{A}_{532}=1 /$ slope of the standard curve, MA mol. weight $=72.03$ $\mathrm{g} / \mathrm{mol}, \mathrm{DF}=$ dilution factor $=5 \mathrm{~mL} / 100 \mathrm{~mL}$ and $\mathrm{M}=$ sample mass.

TBA Value is now determined using $\mathrm{K}$ (constant) derived from Equation 1 and the absorbance read on the spectrophotometer.

$$
\text { TBA Value }=\mathrm{K} \times \mathrm{A}_{532}
$$

TBA Value $=$ mg malonaldehyde/kg sample

\section{Oxymyoglobin Concentration Determination}

Oxymyoglobin concentration was determined on days 1, 3, 5 and 7 as described by Faustman and Phillips (2001). Briefly, 15g sample was ground in a Waring blender with approximately $50 \mathrm{~mL}$ of liquid nitrogen until the sample was completely pulverized. Three grams of powdered sample were placed back in the blender with 30mL myoglobin buffer (40 mM potassium phosphate) and the mixture was blended until homogenous. The sample was placed in centrifuge bottles and incubated at $4{ }^{\circ} \mathrm{C}$ for 1 hour. The centrifuge bottles were centrifuged at 15,000 rpm for 30 minutes. The sample was filtered 
and transferred into a cuvette. The spectrophotometer was read at $418 \mathrm{~nm}$ and $\mathrm{mg}$ ferrous myoglobin/g of sample was determined with the following calculation:

$$
\text { Molar Concentration of Myoglobin }=\operatorname{Abs} 418 /\left(\varepsilon^{*} b\right)
$$

where $\varepsilon$ is 128000 and $\mathrm{b}$ is the cuvette pathlength.

$$
\text { Myoglobin }(\mathrm{g} / \mathrm{L})=\text { Molar Conc. of Myoglobin* Molecular Weight of Myoglobin }
$$

where the Molar Concentration of Myoglobin was derived from Equation 2 and the Molecular Weight of Myoglobin is equal to 16946 grams/mole (beef).

\section{Flavor Volatile Analysis}

Flavor volatile analysis was conducted on cooked patties on days 1, 3 and 7 as described by Fernando et al. (2003) with some revisions. Patties were cooked in an impingement oven (Blodgett Combi Oven, Model 00S8E/AA; Burlington, VT, USA) at $204^{\circ} \mathrm{C}$ for $7 \mathrm{~min}$. Cooked patties were mashed and $5 \mathrm{~g}$ sample was weighed into $10 \mathrm{~mL}$ auto-SPME sample vials (Supelco, Bellefonte, PA, USA) and $100 \mu \mathrm{L}$ internal standard (2-methyl pentonal in distilled water) was added. Sample order was randomized before each analysis and duplicates were run in the same sequence. Aluminum vial caps containing Teflon-lined septa (Supelco) were crimped. The vials were heated on a hotplate to $70^{\circ} \mathrm{C}$ for $30 \mathrm{~min}$ and then allowed to return to room temperature. A Varian 3400CX gas chromatograph (Varian Associates, Walnut Creek, CA, USA), equipped with a Varian 8200 auto sampler in the SPME mode containing a 50/30 $\mu \mathrm{m}$ DVB/CAR/PDMS stableflex SPME fiber (Supelco) was used to analyze the flavor volatile content in the headspace. An absorption time of 20 min and desorption time of 3 min in the splitless mode was used for this purpose. The gas chromatographic column 
used was a DB-5 column. Column flow (He) and split flow were 1 and $100 \mathrm{~mL} / \mathrm{min}$, respectively, at 10 psi column head pressure. Injector and detector (FID) temperatures were maintained at $250^{\circ} \mathrm{C}$ and $275^{\circ} \mathrm{C}$, respectively. The column temperature was maintained at $35^{\circ} \mathrm{C}$ for $3 \mathrm{~min}$ and raised to $220^{\circ} \mathrm{C}$ at $5^{\circ} \mathrm{C} / \mathrm{min}$, then to $250^{\circ} \mathrm{C}$ at $10^{\circ} \mathrm{C} / \mathrm{min}$ and held at $250^{\circ} \mathrm{C}$ for $2 \mathrm{~min}$. The data were processed using a Varian Star (Varian Associates) chromatographic workstation. Quantitative estimation of flavor volatile concentration was achieved using an internal standard method. A Varian GC 3400CX (Varian Associates), equipped with a 1078 programmable injector connected to a Varian Saturn 2000 Mass spectrometer with an ion trap detector was used for GC-MS analysis. Volatiles were separated using a DB-5 fused silica capillary column. Helium carrier gas flow rate was $1 \mathrm{~mL} / \mathrm{min}$ and injector, transfer line and ion trap temperatures were 250 , $250,150^{\circ} \mathrm{C}$, respectively. Desorption time of SPME fiber at the injection port was 4 min in the splitless mode and the post desorption split flow was $100 \mathrm{~mL} / \mathrm{min}$. Identification of 2,3 Octanedione was established using mass spectra comparison with the NIST 1992 and Wiley 5 libraries, retention indices of standards and literature values. 2,3 Octanedione was chosen as a flavor volatile of interest because its mushroom-like odor (Ulrich, et. al, 2001) is an indicator of Warmed Over Flavor (WOF).

\section{Sensory Panel}

A team of eight, trained sensory panelists evaluated patty color, percent discoloration and patty odor on days 1, 3, 5 and 7 using the methods described by Rhee $e t$ al. (1997). Patties were placed in $15.24 \mathrm{~cm}$ diameter, glass petri dishes for thirty minutes before sensory evaluation at room temperature $\left(21^{\circ} \mathrm{C}\right)$. Plastic watch glasses were placed 
on each glass dish to trap the odor volatiles. Two minutes was timed between panelists to allow for the re-accumulation of volatiles. Panelists briefly lifted the watch glasses to sniff the patties and immediately recorded the off-odors detected. Off-odor descriptors included 'putrid', 'sour' and 'fruity', and each descriptor had an 8-point intensity scale (0 $=$ no off odor, $7=$ extreme off odor). Panelists assigned odor intensity for each descriptor to each patty. References for each off-odor were available to panelists throughout the sensory evaluation. Strawberry yogurt was a marker for a 'fruity' off-odor with an intensity of 6 and buttermilk had an intensity of 4 on the sour scale. Additionally, intensity markers were available to panelists at each evaluation, with 8 vials of increasing concentration of vanilla to water $(0-100 \%$ water, $0 \%$ vanilla and $7-0 \%$ water, $100 \%$ vanilla). Following odor analysis, the watch glasses were removed and the patties were placed under a MacBeth lighting apparatus (Model EBX-22; 60W Incandescent bulb; Kollmorgen Corporation, Newburgh, New York, USA). Panelists evaluated percent discoloration based on an 8 -point scale $(0=$ no discoloration, $1=1-12.5 \%$ discoloration, $8=$ complete discoloration). Pie charts with increasing portions of discolored area were provided for panelists at each sensory evaluation as a percent discoloration visual aid. Panelists also evaluated lean color of the patties also under the MacBeth using a predetermined scale as described by Montgomery et al. 2003, where 1=dark brownishgreenish gray, 2=light brownish-greenish gray, 3=light gray, 4=moderately dark red, $5=$ slightly dark red, $6=$ cherry red, $7=$ moderately light cherry red, $8=$ very light cherry red. 


\section{Objective Color Determination}

External $\mathrm{L}^{*}, \mathrm{a}^{*}$ and $\mathrm{b}^{*}$ color values were measured on raw patties on days $1,3,5$ and 7 immediately before sensory panel evaluation using a Minolta Chromameter (Model CR-410, Minolta Camera Co., Ltd., Osaka, Japan; 5cm aperture, illuminant C). Three readings were collected for each patty and averaged to account for variation in the sample. The Minolta was calibrated on every data collection day, using polyvinyl chloride placed on a white calibration plate.

\section{Statistical Analysis}

Statistical analysis was performed using the MIXED procedure of SAS (Version 9.2, SAS Inst., Cary, NC USA) with fat percentage as a covariate. $\mathrm{P}<0.05$ was used to determine significance for meat characteristics. The model included the fixed effects of treatment and all relevant interactions. A t-test was used to determine differences in net value at the $\mathrm{P}<0.10$ level.

\section{RESULTS AND DISCUSSION}

\section{Fat Content}

No differences in fat content were found between treatments $(P>0.05)$. The mean fat percentage for traditional patties was $17.7 \%$ and $17.3 \%$, data not presented in tabular form, for innovative patties. The similarity in means between treatments was expected because all intermuscular fat was excluded from the grinds, leaving only intramuscular fat contribute to fat percentage. Fat percentage was used as a covariate in all statistical analyses. 


\section{Oxymyoglobin Concentration}

The effect of cut-out on oxymyoglobin concentration is shown in Table 1. Oxymyoglobin concentration was not different $(P>0.05)$ between treatments, but content decreased with days of storage $(P<0.05)$. The decrease in concentration of oxymyoglobin by day of storage is due to the oxidation of oxymyoglobin to metmyoglobin. Our data agrees with the findings of Balentine, et al. (2006), who showed that oxymyoglobin decreased over storage. The concentration of oxymyoglobin has a direct and positive relationship with $\mathrm{a}^{*}$ value (greenness to redness), as well as sensory panel acceptance. The decrease in oxymyoglobin content over time corresponds with the increase in percent discoloration and decrease in color score determined by the sensory panel, which also suggests an increased relative proportion of metmyoglobin over storage.

\section{Objective Color Determination}

The effect of cut-out on Minolta Chromameter $\mathrm{L}^{*}, \mathrm{a}^{*}$ and $\mathrm{b}^{*}$ readings is shown in Table 1. Objective color readings showed no differences $(P>0.05)$ between TRA and INN patties for $\mathrm{L}^{*}, \mathrm{a}^{*}$ or $\mathrm{b}^{*}$. The $\mathrm{a}^{*}$ values decreased throughout storage $(P<0.05)$, which is in agreement with the decreasing oxymyoglobin concentration during retail display. Color change from day 0 to all other days of storage for $\mathrm{a}^{*}$ and $\mathrm{b}^{*}$ was higher $(P$ $<0.05$ ) for TRA than for INN, indicating more substantial fading in TRA patties. 


\section{Sensory Panel}

The effect of cut-out on sensory panel color and percent discoloration is shown in Table 1. No differences were observed in patty percentage discoloration or color score between treatments on any days $(P>0.05)$, but patty percentage discoloration increased with days of storage $(P<0.05)$, while patty color decreased over storage $(P<0.05)$. The accumulation of metmyoglobin, with the deterioration of oxymyoglobin, has been well documented as the cause of undesirable color change in beef (Suman and Joseph, 2013; Mancini and Hunt, 2005). According to Mancini and Hunt (2005) consumers strongly discriminate against faded beef, and the visual assessment by consumers is the "gold standard" in determining consumer acceptability. Although a change in redness, indicated by $\mathrm{a}^{*}$, was detected by the Minolta Chromameter, a difference in percent discoloration or color score was not detected by the sensory panel. This shows that although a statistical difference may exist in rate of patty fading, it is not substantial enough to be detected by consumers.

The effect of cut-out on sensory panel odor analysis is shown in Table 3. No differences $(P>0.05)$ were found on any days for 'fruity,' 'putrid' or 'sour' notes between INN and TRA patties in the sensory panel. 'Fruity' and 'putrid' notes were higher $(P<0.05)$ on day 7 compared to the other days of storage. Both of the 'fruity' and 'putrid' notes, which are likely more related to spoilage than oxidation, did not rise to a 1 on the intensity scale, indicating that spoilage had not occurred during the length of this study. However, 'sour' notes, which reveal the development of the "wet cardboard" odor associated with Warmed Over Flavor (WOF) (Tims and Watts, 1958), increased with days of storage $(P<0.05)$, indicating the continued buildup of secondary products of 
lipid oxidation throughout the study. These results were similar to those reported by Rhee et al. (1997), which showed no change in 'fruity' and 'putrid' odors from day 0 to 8 , but an increase in 'sour' odors over storage.

\section{Lipid Oxidation}

The effects of cut-out on TBARS development are shown in Table 2. No differences $(P>0.05)$ in TBARS were observed between TRA and INN patties, with mean values of 0.10 and 0.09 , respectively. These values are much lower than those reported by other researchers with similar shelf-life studies (Raines, et al. 2010; Rhee, et al. 1997) which may be due to different packaging and storage conditions. Liu, et al., (1996) showed that when beef is aged for 14 days, TBARS levels at day 1 after grinding

are above 1 . Trim from this study was sourced at $3 \mathrm{~d}$ carcass aging and was never subject to temperature abuse. TBARS increased $(P<0.05)$ over storage between days 2 and 6 , with mean values of 0.08 and 0.10 , respectively. These results agree with Johnston, et al. (2005), who reported that TBARS increased $(P<0.05)$ in raw beef patties over a 6-day, refrigerated storage period.

\section{Flavor Volatile Analysis}

The effect of cut-out on 2,3 Octanedione concentration is shown in Table 3. 2,3 Octanedione was chosen as a flavor volatile of interest because its mushroom-like odor (Ulrich, et. al, 2001) is associated with Warmed Over Flavor (WOF), and its accumulation is an indicator of lipid oxidation (St. Angelo, 1987). The concentration of 2,3 Octanedione was not different $(P>0.05)$ between INN and TRA patties. 2,3 
Octanedione content was higher on day 7 than days 1 and 3 . The accumulation of 2,3 Octanedione over storage indicates the continued oxidation of lipids in that timeframe, confirming the lipid oxidation results found in the raw patties. These results agree with Spanier et al., who showed that TBARS was positively correlated with WOF descriptors over a four-day storage period (1992). Vinyl ketones like 2,3 Octanedione are detectable between 0.00002-0.007 ppm (Palm, 2002). 2,3 Octanedione had reached 0.016 ppm by Day 7; therefore, sensory panelists were likely detecting this WOF and characterizing it as a "sour" off-odor.

\section{Correlations}

Correlations between indicators of oxidative and color stability are shown in Table 4. Day 6 TBARS data was moderately and negatively correlated with the concentration of oxymyoglobin on day 7, indicating the conversion from ferrous myoglobin to metmyoglobin as TBARS increased over storage. Additionally, day 2 TBARS is negatively correlated with $\mathrm{a}^{*}$ values on all days and Day 6 TBARS is negatively correlated with $a^{*}$ values on days 3,5 and 7 . These findings are supported by Zakrys et al. (2008) which found that TBARS is negatively correlated with oxymyoglobin content, and also with $\mathrm{a}^{*}$ value. As oxymyoglobin is oxidized to metmyoglobin, due to lipid oxidation secondary products, $\mathrm{a}^{*}$ value decreases as well.

Furthermore, Day 3 oxymyoglobin content is negatively correlated with Day $5 \mathrm{a}^{*}$ value and tends to be negatively correlated with Day $3 \mathrm{a}^{*}$ value. This pattern is indicative of the conversion of oxymyoglobin to metmyoglobin, which results in a loss of the bright, 
red color associated with oxymyoglobin. As the patty fades to brown metmyoglobin, the Minolta a* value drops in response.

The connection between myoglobin oxidation and lipid oxidation has been studied extensively and is well documented (Faustman and Cassens, 1990). Lipid oxidation secondary products (nonenals and pentanals) are highly pro-oxidative secondary products that have been shown to significantly accelerate the conversion of ferrous myoglobin to metmyoglobin in muscle (Lynch and Faustman, 2000). Likewise, the heme pigments myoglobin and hemoglobin are known to initiate the lipid oxidation process (Younathan and Watts, 1960). The increase in secondary lipid oxidation products over time indicates that these chemicals are accumulating and have the potential to promote myoglobin oxidation. Furthermore, those lipid oxidation products are often further broken down into compounds that, even at concentrations below 1ppm, can result in altered flavors and odors (Frankel, 1984). Additionally, the conversion of oxymyoglobin to metmyoglobin is also responsible for the degradation of desirable color, and the resulting decrease in consumer acceptability of meat over time. These processes were all observed in our analysis. As our lipid oxidation indicators increased over time, the oxymyoglobin content decreased in response, indicating a conversion to metmyoglobin. Furthermore, as lipid oxidation secondary products increased, the accumulation of off-odors also increased, visible in both the sensory panel and flavor volatile analysis. Finally, the increase in relative metmyoglobin content lead to a decrease in color score and an increase in percent discoloration, as well as a decrease in Minolta Chromameter a* value. The buildup of undesirable off-odors, coupled with the 
degradation of acceptable patty color by day 7 results in a decline in consumer acceptability. In this study, both treatments exhibited normal degradation of oxidative and color stability, and none of our data indicate a difference in consumer acceptability between TRA and INN patties.

\section{CONCLUSIONS}

The exclusion of the Serratus ventralis, Supraspinatus, Infraspinatus and the Teres major, from the chuck did not have any detrimental impacts on the oxidative or color stability of the resulting ground chuck. The rate of fading detected within the TRA patties by the Minolta Chromameter occurred at a faster rate than the INN patties; however, this was not detected by the trained panel. It can be concluded that customers would also not be able to discern a difference between TRA patties and INN patties. Therefore, meat processors can safely exclude those higher priced, whole muscle cuts from the chuck without detrimental consequences on the resulting ground beef. Based on this information, meat processors can isolate those muscles for individual retail sale without an impact on consumer acceptability of the ground chuck. 
Table 1.

Color analysis on raw patties on days $1,3,5$ and 7 after grinding.

\begin{tabular}{|c|c|c|c|c|c|c|c|c|c|}
\hline & \multicolumn{2}{|c|}{ Cut-out $^{3}$} & \multicolumn{4}{|c|}{ Day } & \multirow[t]{2}{*}{ SEM } & \multicolumn{2}{|c|}{ p-value } \\
\hline & Traditional $^{1}$ & Innovative $^{2}$ & 1 & 3 & 5 & 7 & & Cut-out $^{3}$ & Day \\
\hline $\mathrm{OxyMb}^{4}$ & 2.99 & 2.96 & $3.14^{\mathrm{a}}$ & $3.04^{\mathrm{b}}$ & $2.9^{\mathrm{c}}$ & $2.83^{c}$ & 0.038 & 0.3402 & $<0.0001$ \\
\hline Panel Color ${ }^{5}$ & 5.3 & 5.1 & $5.8^{\mathrm{a}}$ & $5.6^{\mathrm{a}}$ & $5.2^{b}$ & $4.1^{\mathrm{c}}$ & 0.126 & 0.0916 & $<0.0001$ \\
\hline Panel Discoloration ${ }^{6}$ & 2.1 & 2.3 & $0.9^{\mathrm{d}}$ & $1.4^{\mathrm{c}}$ & $2.2^{\mathrm{b}}$ & $4.4^{\mathrm{a}}$ & 0.127 & 0.1016 & $<0.0001$ \\
\hline $\mathrm{L}^{*}$ & 53.65 & 53.5 & $53.64^{\mathrm{a}}$ & $53.09^{b}$ & $53.6^{\mathrm{a}}$ & $54^{\mathrm{a}}$ & 0.199 & 0.3949 & 0.0081 \\
\hline $\mathrm{L}^{*} \operatorname{diff}^{7}$ & -0.03 & -0.07 & $-0.01^{b}$ & $0.34^{\mathrm{a}}$ & $-0.04^{\mathrm{b}}$ & $-0.51^{\mathrm{c}}$ & 0.112 & 0.7227 & $<0.0001$ \\
\hline$a^{*}$ & 13.17 & 13.06 & $17.14^{\mathrm{a}}$ & $13.95^{\mathrm{b}}$ & $12^{\mathrm{c}}$ & $9.39^{d}$ & 0.243 & 0.4887 & $<0.0001$ \\
\hline$a^{*} \operatorname{diff}^{7}$ & $6.61^{\mathrm{a}}$ & $5.85^{\mathrm{b}}$ & $2.25^{\mathrm{d}}$ & $5.48^{\mathrm{c}}$ & $7.54^{\mathrm{b}}$ & $9.65^{\mathrm{a}}$ & 0.23 & 0.0002 & $<0.0001$ \\
\hline$b^{*}$ & 6.53 & 6.42 & $7.33^{\mathrm{a}}$ & $6.28^{\mathrm{b}}$ & $6.14^{\mathrm{b}}$ & $6.15^{b}$ & 0.067 & 0.0561 & $<0.0001$ \\
\hline$b^{*} \operatorname{diff}^{7}$ & $1.33^{\mathrm{a}}$ & $1.01^{\mathrm{b}}$ & $0.38^{c}$ & $1.37^{\mathrm{b}}$ & $1.61^{\mathrm{a}}$ & $1.33^{\mathrm{b}}$ & 0.085 & 0.0003 & $<0.0001$ \\
\hline
\end{tabular}

Means within the same row followed by a different letter differ significantly $(\mathrm{p}<0.05)$.

${ }^{1}$ Trim from neck and shank, half clod and half of chuck roll included in grind.

${ }^{2}$ Trim from neck and shank, half clod heart and half of chuck eye roll were included in grind; Infraspinatus, Supraspinatus, Teres major and Serratus ventralis were excluded from the grind

${ }^{3}$ Cut-out, traditional or innovative ground beef blend

${ }^{4}$ Oxymyoglobin concentration (mg oxymyoglobin/g sample)

${ }^{5}$ Panel Color: $1=$ dark brownish-greenish gray, $8=$ very light cherry red

${ }^{6}$ Panel Discoloration: $1=0 \%$ discoloration, $1=1-12.5 \%$ discoloration, $8=$ complete discoloration

${ }^{7} \mathrm{~L}^{*}, \mathrm{a}^{*}, \mathrm{~b}^{*}$ diff: Minolta Chromameter readings were taken on day 0 and compared with measurements from days $1,3,5$ and 7 (Day $\mathrm{n}-$ day 0 ) 
Table 2.

Thiobarbituric Acid Reactive Substances (TBARS) analysis on days 2 and 6 after grinding.

\begin{tabular}{|c|c|c|c|c|c|c|c|}
\hline \multirow[b]{2}{*}{ Day of Storage } & \multicolumn{2}{|c|}{ Cut-out $^{3}$} & \multicolumn{2}{|c|}{ Day } & \multirow[t]{2}{*}{ SEM } & \multicolumn{2}{|c|}{ p-value } \\
\hline & Traditional $^{1}$ & Innovative $^{2}$ & 2 & 6 & & Cut-out $^{3}$ & Day \\
\hline TBARS (mg TBA/kg sample) & 0.10 & 0.09 & $0.08^{\mathrm{b}}$ & $0.10^{\mathrm{a}}$ & 0.007 & 0.295 & 0.024 \\
\hline
\end{tabular}

Means within the same row followed by a different letter differ significantly $(\mathrm{p}<0.05)$.

${ }^{1}$ Trim from neck and shank, half of clod and half of chuck roll included in grind.

${ }^{2}$ Trim from neck and shank, half clod heart and half of chuck eye roll were included in grind; Infraspinatus, Supraspinatus, Teres major and Serratus ventralis were excluded from grind.

${ }^{3}$ Cut-out: traditional or innovative ground beef blend 
Table 3.

Sensory analysis on raw patties on days $1,3,5$ and 7 and for flavor volatiles (2,3 Octanedione) on cooked patties on days 1,3 and 7 .

\begin{tabular}{|c|c|c|c|c|c|c|c|c|c|}
\hline \multirow[b]{2}{*}{ Day of Storage } & \multicolumn{2}{|c|}{ Cut-out $^{3}$} & \multicolumn{4}{|c|}{ Day } & \multirow[t]{2}{*}{ SEM } & \multicolumn{2}{|c|}{$\mathrm{p}$-value } \\
\hline & Traditional $^{1}$ & Innovative $^{2}$ & 1 & 3 & 5 & 7 & & Cut-out $^{3}$ & $\mathrm{D}$ \\
\hline 2,3 Octanedione (ppm) & 0.011 & 0.012 & $0.009^{\mathrm{b}}$ & $0.010^{\mathrm{b}}$ & N/A & $0.016^{\mathrm{a}}$ & 0.0004 & 0.697 & $<0.1$ \\
\hline Sour Off-Odor Intensity (Score $0-7)^{\mathrm{c}}$ & 1.0 & 0.9 & $0.2^{\mathrm{d}}$ & $0.6^{\mathrm{c}}$ & $1.3^{\mathrm{b}}$ & $1.6^{\mathrm{a}}$ & 0.056 & 0.449 & $<0 .($ \\
\hline Fruity Off-Odor Intensity $(\text { Score } 0-7)^{\mathrm{c}}$ & 0.2 & 0.2 & $0.2^{\mathrm{b}}$ & $0.1^{b}$ & $0.2^{\mathrm{b}}$ & $0.4^{\mathrm{a}}$ & 0.048 & 0.995 & 0.0 \\
\hline Putrid Off-Odor Intensity $(\text { Score } 0-7)^{\mathrm{c}}$ & 0.3 & 0.3 & $0.1^{\mathrm{b}}$ & $0.2^{\mathrm{b}}$ & $0.2^{\mathrm{b}}$ & $0.8^{\mathrm{a}}$ & 0.055 & 0.910 & $<0 .($ \\
\hline
\end{tabular}

Means within the same row followed by a different letter differ significantly $(\mathrm{p}<0.05)$.

${ }^{1}$ Trim from neck and shank, half clod and half of chuck roll included in grind.

${ }^{2}$ Trim from neck and shank, half clod heart and half of chuck eye roll were included in grind; from grind. Infraspinatus, Supraspinatus, Teres majo Serratus ventralis were excluded

${ }^{3}$ Cut-out, traditional or innovative ground beef blend

${ }^{4}$ Off Odor Intensity Scale: 0-7 (O = no off odor, 7 = extreme off odor) 


\section{Table 4.}

Correlations between the Concentration of Oxymyoglobin, Minolta a* Value and Concentration of TBA

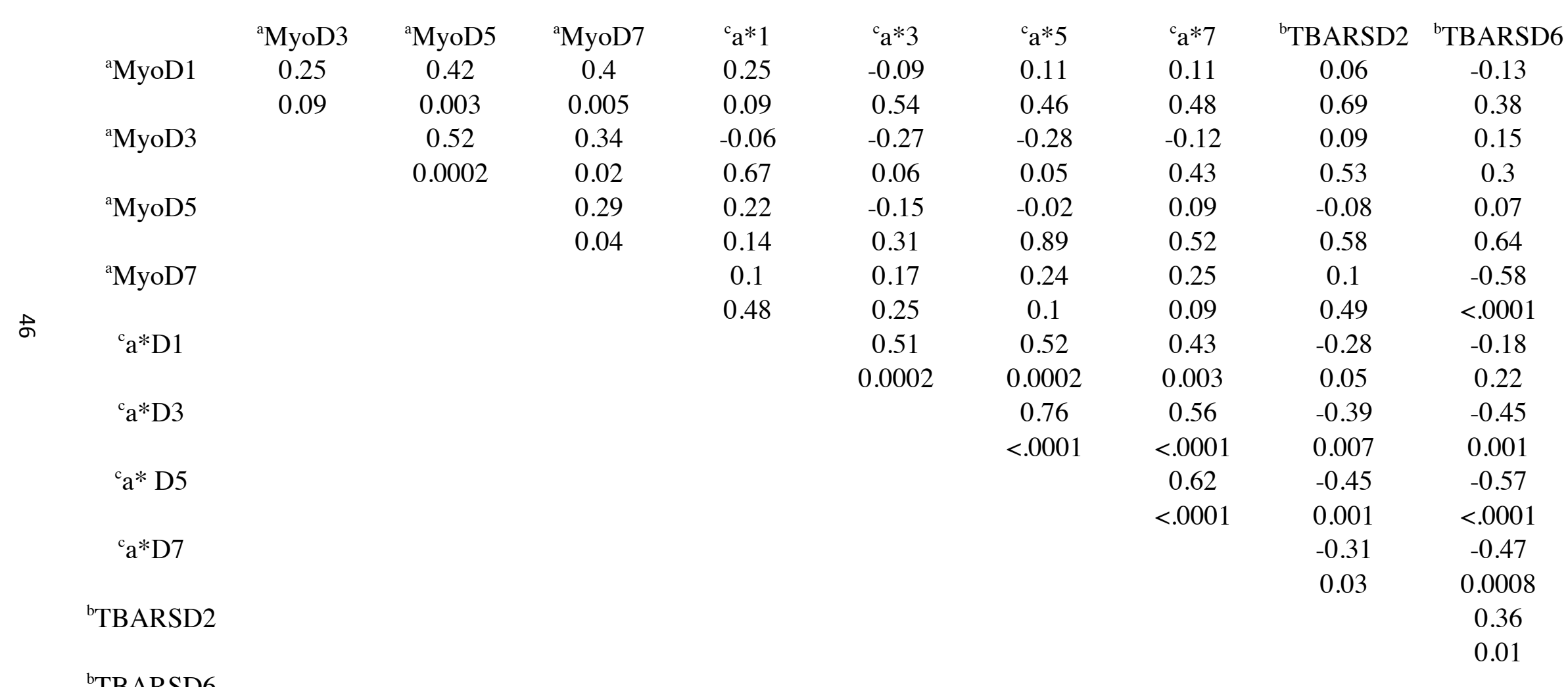

${ }^{a}$ Myo: Concentration of ferrous myoglobin (mg/g sample) on D (Day) 1, 3, 5 or 7 .

${ }^{\mathrm{b}}$ TBARS: Concentration TBARS (mg TBA/kg meat) on D (Day) 2 or 6.

ca*: Minolta Chromameter a* Value on D (Day) 1, 3, 5 or 7. 


\section{LITERATURE CITED}

Al-Suwaiegh, S., K. C. Fanning, R. J. Grant, C. T. Milton, and T. J. Klopfenstein. 2002. Utilization of distillers grains from the fermentation of sorghum or corn in diets for finishing beef and lactating dairy cattle. Journal of Animal Science. 80:11051111.

AMSA. 2012. Myoglobin chemistry. Pages 3-10 in Meat Color Measurement Guidelines. M. Hunt and A. King, ed. American Meat Science Association, Champaign, IL.

Ang, C. Y. W. and L. L. J. Young. 1989. Factors relating to oxidative stability of cooked broiler breast patties treated with sodium tripolyphosphate. Journal of Food Science. 54:1151-1154.

Arihara, K., M. Itoh, and Y. Kondo. (1989) Identification of bovine skeletal muscle metmyoglobin reductase as an NADH-Cytochrome b5 reductase. Japanese Journal of Zootechnology Science 60:46-56.

Arthur, C. L., J. Pawliszyn. 1990. Solid-phase Microextraction with Thermal Desorption using Fused Silica Optical Fibers. Anal. Chemistry. 62:2145-2148.

Baigrie, B. 2003. Defining off-flavors and taints. In: Taints and Off-Flavours in Foods. B. Baigrie, ed. Woodhead Publishing, Ltd. Caimbridge, England.

Bailey, M. E. and R. G. Einig. 1989. Reaction flavors of meat. In Thermal Generation of Aromas. T. H. Parliament, R. J. McGorrin and C. T. Ho, ed. ACS Symposium Series. 409:421-432.

Bailey, M. E., H. P. Dupuy, and M. G. Legendre. 1980. The analysis and control of undesirable flavors in foods and beverages. Advancements in Food Research. G. Charalambous, ed. Academic Press: New York, p. 31.

Balentine, C. W., P. G. Crandall, C. A. O’Bryan, D. Q. Duong and F. W. Pohlman. 2006. The pre- and post-grinding application of rosemary and its effects on lipid oxidation and color during storage of ground beef. Meat Science. 73:413-421.

Baron, C. and H. J. Anderson. 2002. Myoglobin-induced lipid oxidation. A review. Journal of Agricultural and Food Chemistry. 50:3887-3897.

Berardesca, E., P. Elsner and H. I. Maibach. 1995. Bioengineering of the Skin: Cutaneous Blood Flow and Erythema. CRC Press, LLC, Boca Raton, Florida.

Carpenter, C. E., D. P. Cornforth, and D. Whittier. 2001. Consumer preferences for beef color and packaging did not affect eating satisfaction. Meat Science. 57:359-363.

Cesa, S. 2004. Journal of Agricultural Food Chemistry, 52:2119-2122. 
Chalfant, J. A. and J. M. Alston. 1988. Accounting for changes in tastes. Journal of Political Economy. 96:391-410.

Chan, K. M., E. A. Decker, C. M. Faustman. 1994. Endogenous skeletal muscle antioxidants. Critical Reviews in Food Science and Nutrition. 34:403-426.

Claus, J. R. 2007. Color changes in cooked beef. National Cattleman's Beef Association. www.beefresearch.org

Cornforth, D. P., P. Jayasingh. 2004. Chemical and physical characteristics of meat color and pigment. Pages 249-256 in Encyclopedia of Meat Sciences. W. K. Jensen, C. Devine and M. Dikeman, ed. Elsevier Sci. Ltd., Oxford, UK.

Cross, H. R., R. Leu, M. F. Miller. 1987. Scope of warmed-over flavor and its importance to the meat industry. Pages 1-18 in Warmed-Over Flavor of Meat. A. J. St. Angelo and M. E. Bailey, ed. Academic Press, Inc. New York, NY.

Davis, C. G. and B. H. Lin. 2005. Factors affecting U.S. beef consumption. United States Department of Agriculture, Economic Research Service, Agricultural Statistics Board. Washington, D.C.

Decker, E. A., S. A. Livisay and S. Zhou. 2000. In Antioxidants in Muscle Foods. E. A. Decker, C. M. Faustman and C. J. Lopez-Bote, eds. Wiley-Interscience, John Wiley \& Sons, Inc. Publication.

Devasagayam, T. P. A., K. K. Boloor and T. Ramasarma. 2003. Methods for estimating lipid peroxidation: an analysis of merits and demerits. Indian Journal of Biochemistry and Biophysics. 40:300-308.

Dow D. L., B. R. Wiegand, M. R. Ellersieck, and C. L. Lorenzen. 2011. Prediction of fat percentage within marbling scores on beef longissimus muscle using three different fat determination methods. J. Anim. Sci. 89:1173-1179.

Erickson, M. C. 2002. Lipid oxidation of muscle foods. Pages 365-412 in Food Lipids: Chemistry, Nutrition, and Biotechnology. C. C. Akoh, D. B. Min, Eds. Marcel Dekker: New York.

Farmer, L. J. 1994. The role of nutrients in meat flavour formation. Proceedings of the Nutrition Society. 53:327-333.

Faustman, C. and A. Phillips. 2001. Measurement of discoloration in fresh meat. In: Current Protocols in Food Analytical Chemistry. John Wiley \& Sons, Inc., New York, NY.

Faustman, C., R. G. Cassens. 1990. The biochemical basis for discoloration in fresh meat: a review. Journal of Muscle Foods. 1:217-243. 
Faustman C., R. G. Cassens, D. M. Schaefer, D. R. Buege, S. N. Williams and K. K. Scheller. 1989. Improvement of pigment and lipid stability in Holstein steer beef by dietary supplementation with vitamin E. J. Food Sci. 54:858-62.

Faustman, C., D.C. Lieber, T.D. McClure and Q. Sun. 1999. $\alpha, \beta$-Unsaturated aldehydes accelerate oxymyoglobin oxidation. Journal of Agricultural and Food Chemistry. 47:3140-3144.

Faustman, C., Q. Sun, R. Mancini and S. P. Suman. 2010. Myoglobin and lipid oxidation interactions: Mechanistic bases and control. Meat Science. 86:86-94.

Faustman, C., M. Yin and D. Nadeau. 1992. Color stability, lipid stability and nutrient composition of red and white veal. Journal of Food Science. 57:302-317.

Fenaroli, G. 1971. Fenaroli's Handbook of Flavour Ingredients. T. E. Furia, N. Bellanca, Eds. Chemical Rubber Co., Cleveland, $\mathrm{OH}$.

Fernando, L. N., E. P. Berg, and I. U Grün. 2003. Quantification of hexanal by automated SPME for studying dietary influences on the oxidation of pork. J. Food Composition and Analysis. 16:179-188.

Fox, J. B., Jr. 1966. The chemistry of meat pigments. Journal of Agricultural and Food Chemistry. 14:207-210.

Frankel, E. N. 1984. Recent Advances in the Chemistry of Rancidity of Fats. Pages 87118 in Recent Advances in the Chemistry of Meat. 47, Ch. 6.

Frankel, E. N. 1984. Lipid Oxidation: mechanisms, products and biological significance. Journal of the Association of Oil Chemist's Society. 61:1908-1917.

Gill, R. K., D. L. VanOverbeke, B. Depenbusch, J. S. Drouillard and A. DiCostanzo. 2008. Impact of beef cattle diets containing corn or sorghum distillers grains on beef color, fatty acid profiles, and sensory attributes. Journal of Animal Science. 86:923-935.

Gordon, M. The development of oxidative rancidity in foods. 2001. In Antioxidants in Food. J. Pokorny, N. Yanishlieva and M. Gordon, ed. Woodhead Publishing Limited, Cambridge, England.

Gray, J. I. 1978. Measurement of lipid oxidation: a review. Journal of the American Oil Chemists' Society. 55:539-546.

Green, B. E., I. Hsin, M. W. Zipser. 1971. Retardation of oxidative color changes in raw ground beef. Journal of Food Science. 36:940-942. 
Greene, B. E. 1969. Lipid oxidation and pigment changes in raw beef. J. Food Sci., 34:110-113.

Greene, B. E., I. Hsin, M.W. Zipser. 1971. Retardation of oxidative color change in raw ground beef. Journal of Food Science, 36:940-944.

Haurowitz, F., P. Schwerin, and M. Yenson. 1941. Destruction of hemin and hemoglobin by the action of unsaturated fatty acids and oxygen. J. Biological Chemistry. 140, 353.

Hood, D. E., E. B. Riordan. 1973. Discoloration in prepackaged beef: measurement by reflectance spectroscopy and shopper discrimination. Journal of Food Technology, 8:333-343.

Hood, D.E. 1975. Pre-slaughter injection of sodium ascorbate as a method of inhibiting metmyoglobin formation in fresh beef. Journal of Science of Food and Agriculture. 26:85-90.

Hornstein, I. and P. F. Crowe. 1960. Flavor studies on beef and pork. Journal of Agricultural and Food Chemistry. 8:494-498.

Insani, E. M., A. Eyherabide, G. Grigioni, A. M. Sancho, N. A. Pensel and A. M. Descalzo. 2008. Oxidative stability and its relationship with natural antioxidants during refrigerated retail display of beef produced in Argentina. Journal of Meat Science. 79:444-452.

Judge, M. D. and E. D. Aberle. 1980. Effect of pre-rigor processing on the oxidative rancidity of ground light and dark porcine muscles. Journal of Food Science. 45:1736-1745.

Kanner, J., S. Harel and R. Jeffe. 1991. Lipid oxidation of muscle food as affected by $\mathrm{NaCl}$. Journal of Agricultural Food Chemistry. 39:1017-1021.

Kataoka, H., H. Lord and J. Pawliszyn. 2000. Applications of solid-phase microextraction in food analysis. Journal of Chromatography A. 880:35-62.

Keller, J. D. and J. E. Kinsella. 1973. Phospholipid changes and lipid oxidation during cooking and frozen storage of raw ground beef. Journal of Food Science. 38:1200-1204.

Kropf, D. 2008. Color Quality in Meat. In Color Quality of Fresh and Processed Foods. C. Culver, ed. ACS Symposium Series; American Chemical Society: Washington, DC.

Koger, T. J., D. M Wulf, A. D. Weaver, C. L. Wright, K. E. Tjardes, K. S. Mateo, T. E. Engle, R. J. Maddock and A. J. Smart. 2010. Influence of feeding various 
quantities of wet and dry distillers grains to finishing steers on carcass characteristics, meat quality, retail-case life of ground beef, and fatty acid profile of longissimus muscle. Journal of Animal Science. 88:3399-3408.

Krzywicki, K. 1982. The determination of haem pigments in meat. Meat Science. 7:2936.

Krzywicki, K. 1979. Assessment of relative content of myoglobin, oxymyoglobin and metmyoglobin at the surface of beef. Meat Science. 3:1-10.

Kubelka, P. 1948. New contributions to the optics of intensely light-scattering materials. Journal of the Optical Society of America. 38:448-457.

Ladikos, D. and V. Lougovois. 1990. Lipid oxidation in muscle foods: a review. Food Chemistry. 35:295-301.

Lea, C. H. 1952. Methods for determining peroxide in lipids. Journal of the Science of Food and Agriculture. 3:586-594.

Ledward, D. A. 1985. Post-slaughter influences on the formation of metmyoglobin in beef muscles. Meat Science. 15:149-171.

Lillard, D. A. 1987. Oxidative deterioration in meat, poultry and fish. In Warmed Over Flavor of Meat. A. J. St. Angelo and M. E. Bailey, ed. Academic Press, Inc., Orlando, Florida.

Linforth, R. S., A. J. Taylor. 1993. Measurement of volatile release in the mouth. Food Chemistry. 48:115-120.

Liu, Q., M. C. Lanari and D. M. Schaefer. 1995. A review of dietary vitamin E supplementation for improvement in beef quality. Journal of Animal Science. 73:3131-3140.

Livingston, D. J. and W. D. Brown. 1981. The chemistry of myoglobin and its reactions. Food Technology. 35:244-252.

Love, J. 1987. Mechanism of iron catalysts of lipid oxidation in warmed-over flavor of meat. In Warmed Over Flavor of Meat. A. J. St. Angelo and M. E. Bailey, ed. Academic Press, Inc., Orlando, Florida.

Lundeen, J. 2011. How is beef hitting the plate? In Beef Issues Quarterly, Vol. 2, No. 4. National Cattleman's Beef Association. http://www.beefissuesquarterly.com/howisbeefhittingtheplate.aspx (accessed on $8 / 10 / 13)$

Lynch, M. P., and C. Faustman. 2000. Effect of aldehyde lipid oxidation products on 
myoglobin. J. Agric. Food Chem. 48:600-604.

Mancini, R. A., M. C. Hunt. 2005. Current research in meat color. Meat Sci. 71:100-121.

Martin, J. N., J. C. Brooks, T. A. Brooks, J. F. Legako, J. D. Starkey, S. P. Jackson and M. F. Miller. 2013. Storage length, storage temperature, and lean formulation influence the shelf-life and stability of traditionally packaged ground beef. Meat Science. 95:495-502.

McCarty, R. 2011. Economic and food choices: consumer response to food price inflation. In Beef Issues Quarterly, Volume 2, Number 4. National Cattleman's Beef Association.

McClements, 2003. Methods of analyzing lipid oxidation in foods. In Analysis of Lipids. D.J. University of Massachusetts, http://people.umass.edu/ mcclemen/581Lipids.html (accessed 8/1/13)

McKenna, D. R., P. D. Mies, B. E. Baird, K. D. Pfeiffer, J. W. Ellebracht, J. W. Savell. 2005. Biochemical and physical factors affecting discoloration characteristics of 19 bovine muscles. Meat Science. 70:217-243.

Meat Retail Case, 2010. http://www.beefretail.org/CMDocs/BeefRetail/research/2010NationalMeatCaseSt udy.pdf Accessed August 12, 2013.

Melton, S. L., P. M. Davidson and J. R. Mount. 1987. Sensory analysis of undesirable flavors in meat. In Warmed Over Flavor of Meat . A.J. St. Angelo, M.E. Bailey, ed. Academic Press, Inc., Orlando, Florida.

Mielche, M. M. 1995. Development of warmed-over flavor in ground turkey, chicken and pork meat during chill storage: a model of the effects of heating temperature and storage time. Z. Lebensm. Unters. Forsch. 200:322-327.

Mitsumoto, M., R. N. Arnold, D. M. Schaefer and R. G. Cassens. 1993. Dietary versus postmortem supplementation of vitamin $\mathrm{E}$ on pigment and lipid stability in ground beef. Journal of Animal Science. 71:1812-1816.

Monahan, F.J. 2000. Muscle foods as a substrate for lipid oxidation. In Antioxidants in Muscle Foods. E. A. Decker, C. M. Faustman, C. J. Lopez-Bote, ed. WileyInterscience, A John Wiley \& Sons, Inc. Publication.

Montgomery, J. L., F. C. Parrish Jr., D. G. Olson, J. S. Dickson and S. Niebuhr. 2003. Storage and packaging effects on sensory and color characteristics of ground beef. Meat Sci. 64:357-363. 
Morrissey, P.A., D.J. Buckley, P.J.A. Sheehy. Vitamin E and meat quality. 1994. Proceedings of the Nutrition Society. 53, 289-295.

Moschini, G. \& Meilke, K. D. 1989. Modeling the Pattern of Structural Change in Meat Demand. American Journal of Agricultural Economics, 71:253-61.

Nour, A. Y. M., M. L. Thonney, G. Armbruster and J.R. Stouffer. 2006. Muscle mineral concentrations as predictors of taste panel sensory attributes of beef. Journal of Food Science. 48:1170-1171.

O'Brien, P. J. 1969. Intracellular mechanisms for the decomposition of a lipid peroxide. Decomposition of a lipid peroxide by metal ions, heme compounds, and nucleophiles. Canadian Journal of Biochemistry. 47:485-492.

O'Keeffe, M. and D. E. Hood. 1982. Biochemical factors influencing metmyoglobin formation in beef from muscles of differing colour stability. Meat Science, 7:209228.

Oxford Biomedical Research. 2012. http://www.funakoshi.co.jp/data/datasheet/OBR/FR45.pdf. Accessed July 30, 2013.

Palm, H. 2002. Detection \& characterization of unwanted off-flavors caused by rancidity through analysis of volatiles. Malaysian Oil Science and Technology. 11:14-18.

Paquette, G. and D. B. Kupranycz. 1985. The Mechanisms of Lipid Autoxidation I. Primary Oxidation Products. Canadian Institute of Food Science and Technology Journal. 18:112-118.

Pearson, A. M., J. D. Love and F. B. Shorland. 1977. Warmed-over flavor in meat, poultry and fish. Pages 2-74 in Advances in Food Research. C.O. Chichester, ed. Academic Press, New York, NY.

Pegg, R. B. 2001. Spectrophotometric measurement of secondary lipid oxidation products. Pages D2.4.1-D2.4.18 in Current Protocols in Food Analytical Chemistry. John Wiley \& Sons, Inc. New York, New York.

Pegg, R. B. and F. Shahidi. 2012. Off-flavors and rancidity in foods. In Handbook of Meat, Poultry, and Seafood Quality. L. M. L. Nollet, ed. John Wiley and Sons, Inc.

Pikul, J., D. E. Leszczynski and F. A. Kummerow. 1984. Relative role of phospholipids, triacylglycerols, and cholesterol esters on malonaldehyde formation in fat extracted from chicken meat. Journal of Food Science. 49:704-708.

Pokorny, J. 2001. Antioxidants in Food, Practical Implications. J. Pokorny, N. 
Yanishlieva and M. Gordon, ed. Woodhead Publishing Limited, Cambridge, England.

Raines, C. R., M. C. Hunt, and J. A.Unruh. 2010. Contributions of muscles of various color stabilities to the overall color stability of ground beef. J. Food Sci. 75:C85C89.

Reddy, I. M., C. E. Carpenter. 1991. Determination of metmyoglobin reductase activity in bovine skeletal muscles. Journal of Food Science. 56:1161-1164.

Redson, B. A. 2011. Beef muscle profiling program created producer and consumer benefits. In Beef Magazine. http://beefmagazine.com/sectors/retail/0501-beefmuscle-program-benefits. Accessed August 10, 2013.

Regmi, A. 2001. Income, demographic shifts, and consumer perceptions are changing global food consumption patterns and trade. In USDA, ERS. A. Regmi, ed. http://www .ers.usda.gov/media/293645/wrs011_1_.pdf . Accessed August 14, 2013.

Renerre, M. 2000. Oxidative processes and myoglobin. In Antioxidants in Muscle Foods: Nutritional Strategies to Improve Quality. E.A. Decker, C. Faustman, C.J. LopezBote, ed. John Wiley \& Sons, Inc. New York, New York.

Rhee K. S., L. M. Krahl, L. M. Lucia and G. R. Acuff. 1997. Antioxidative/antimicrobial effects and TBARS in aerobically refrigerated beef as related to microbial growth. Journal of Food Science. 62:1205-1210.

Rhee, K. S. and Y. A. Ziprin. 1987. Lipid oxidation in retail beef, pork and chicken muscles as affected by concentrations of heme pigments and nonheme iron and microsomal enzymic lipid peroxidation activity. Journal of Food Biochemistry, 11:1-15.

Shahidi, F. and R. B. Pegg. 1994. Hexanal as an indicator of the flavor deterioration of meat and meat products. In Lipids in Food Flavors. C. Ho, ed. ACS Symposium Series. American Chemical Society, Washington D.C., USA.

Shahidi, F. and Y. Zhong. 2005. Lipid oxidation measurement methods. Bailey's Industrial Oil and Fat Products. 6:357-385.

Sinnhuber, R. O. and T. C. Yu. 1977. The 2-thiobarbituric acid reaction, an objective measure of the oxidative deterioration occurring in fats and oils. Journal of Japan Oil Chemists' Society. 26:259-267.

Smith, G. C., K. E. Belk, J. N. Sofos, J. D. Tatum and S. N. Williams. 2000. Economic implications of improved color stability in beef. Pages 397-426 in Antioxidants in Muscle Foods: Nutritional Strategies to Improve Quality. E.A. Decker, C. 
Faustman, C.J. Lopez-Bote, ed. New York: Wiley Intersci.

Spanier, A. M., J. R. Vercellotti and C. James, Jr. 1992. Correlation of sensory, instrumental and chemical attributes of beef as influenced by meat structure and oxygen exclusion. Journal of Food Science. 57:10-15.

St. Angelo, A. J. 1987. Warmed-Over Flavor of Meat. A.J. St. Angelo, M.E. Bailey, ed. Academic Press, Inc. New York, NY.

Steffen, A. and J. Pawliszyn. 1996. Analysis of flavor volatiles using headspace solidphase microextraction. Journal of Agricultural Food Chemistry. 44:2187-2193.

Stewart, M. R., M. W. Zipser and B. M. Watts. 1965. The use of reflectance spectrophotometry for the assay of raw meat pigments. Journal of Food Science. 30:464-469.

Suman, S. P. and P. Joseph. 2013. Myoglobin chemistry and meat color. Annual Rev. Food Sci. Technology. 4:79-99.

Taylor, E. V., K. G. Holt, B. E. Mahon, T. Ayers, D. Norton and L. H. Gould. 2012. Ground beef consumption patterns in the United States, FoodNet, 2006 through 2007. Journal of Food Protection, 75:341-346.

Technomic, 2010. Industry Reports. https://www.technomic.com/Reports_and_Newsletters/Industry_Reports/. (accessed 8/14/13).

Tims, M. J. and B. M. Watts. 1958. Protection of cooked meats with phosphates. Food Technology. 12:240-243.

Troy, D. J. and J. P. Kerry. 2010. Consumer perception and the role of science in the meat industry. Meat Science. 86:214-226.

Ulrich, D., E. Hoberg, T. Bittner, W. Engewald and K. Meilchen. 2001. Contribution of volatile compounds to the flavor of cooked asparagus. Eur. Food Res. Technol. 213:200-204.

USDA. 2010. Average Annual Per Capita Consumption of Meat. United States Department of Agriculture, Economic Research Service, Agricultural Statistics Board. Washington, D.C.

USDA. 2012. U.S. Cattle and Beef Industry, 2002-2011. United States Department of Agriculture, Economic Research Service, Agricultural Statistics Board. Washington, D.C.

USDA. 2013. Choice beef values and spreads and the all-fresh retail value. United States 
Department of Agriculture, Economic Research Service, Agricultural Statistics Board. Washington, D.C.

USDA. 2013. Summary of retail prices and price spreads. United States Department of Agriculture, Economic Research Service, Agricultural Statistics Board. Washington, D.C.

Von Seggern, D. D., C. R. Calkins, D. D. Johnson, J. E. Brickler and B. L. Gwartney. Muscle profiling: characterizing the muscles of the beef chuck and round. Meat Science. 71:39-51.

Warren, H. E., N. D. Scollan, G. R. Nute, S. I. Hughes, J. D. Wood and R. I. Richardson. 2008. Effects of breed and a concentrate of grass silage diet on beef quality. II. Meat stability and flavor. Meat Science. 78:270-278.

Wittenberg, J. B. and B. A. Wittenberg. 2003. Myoglobin function reassessed. Journal of Experimental Biology. 206:2011-2020.

Yang, X. and T. Peppard. 1994. Solid phase micro-extraction for flavor analysis. Journal of Agricultural Food Chemistry. 42:1925-1930.

Younathan, M. T. and B. M. Watts. 1960. Relationship of meat pigments to lipid oxidation. Food Research. 24:728-734.

Zakrys, S. A., M. G. Hogan, P. O'Sullivan, P. Allen and J.P. Kerry. 2008. Effects of oxygen concentration on the sensory evaluation and quality indicators of beef muscle packed under modified atmosphere. Meat Science. 79:648-655.

Zipser, M. W. and B. M. Watts. 1962. A modified 2-thiobarbituric acid (TBA) method for the determination of malonaldehyde in cured meats. Food Technology. 16, 102. 


\section{APPENDIX A: MATERIALS AND METHODS}

\section{A.1 Myoglobin Determination}

According to Faustman and Phillips (2001).

Faustman, C. and A. Phillips. 2001. Measurement of discoloration in fresh meat. In: Current Protocols in Food Analytical Chemistry. John Wiley \& Sons, Inc., New York, NY, F3.3.1 -F3.3.13.

Buffer Solution:

5.44 g Potassium Phosphate per liter deionized water (40mM)

Procedure:

1. Grind $\sim 15 \mathrm{~g}$ of raw sample in a Waring blender with approximately $50 \mathrm{~mL}$ of liquid nitrogen until the sample was completely pulverized.

2. Place sample in a plastic Whirlpak ${ }^{\circledR}$ bag and move it to the freezer immediately until myoglobin determination.

3. Weigh three grams of powdered sample into a weigh boat and place it into the blender with three times its weight $(3 \times 10=30 \mathrm{~mL})$ of myoglobin buffer $(40 \mathrm{mM}$ potassium phosphate).

4. Blend the mixture until homogenous and move to centrifuge bottles and incubate at $4^{\circ} \mathrm{C}$ for 1 hour.

5. Centrifuge the samples at $15,000 \mathrm{rpm}$ for 30 minutes.

6. Filter the sample through Whatman \#1 paper and transfer it into a cuvette.

7. Place the cuvette in the spectrophotometer and determine its absorbance at 418 nm. 
8. Myoglobin content (mg ferrous myoglobin/g of sample) was determined with a simple calculation as follows:

Molar Concentration of Myoglobin $=\operatorname{Abs} 418 /\left(\varepsilon^{*} \mathrm{~b}\right)$

$\varepsilon=128000$

$\mathrm{b}=$ Cuvette Pathlength

Grams/Liter Myoglobin = Molar Concentration of Myoglobin* Molecular Weight of Myoglobin

Molecular Weight of Myoglobin = 16946 grams/mole (beef) 


\section{A.2 Lipid Oxidation (Thiobarbituric Acid Reactive Substances)}

Described by Pegg, 2001.

Pegg, R.B. 2001. Spectrophotometric measurement of secondary lipid oxidation products. In: Current Protocols in Food Analytical Chemistry. (pp D2.4.1D2.4.18) New York: John Wiley \& Sons, Inc.

Antioxidant Solution:

Place $0.5 \mathrm{~g}$ propyl gallate and $0.5 \mathrm{~g}$ Ethylene Diamine Tetracetic Acid (EDTA) into a $100 \mathrm{~mL}$ volumetric flask, dissolve in a small volume of 1:1 ethanol/water solution on a hot plate to promote dissolving. Fill the flask to the $100 \mathrm{~mL}$ mark with $1: 1$ ethanol/water. Prepare fresh daily.

TCA Reagent Solution:

Weigh $200 \mathrm{~g}$ Trichloroacetic Acid (TCA) in a beaker and dissolve crystals in a small volume of water. Add some water and $16 \mathrm{~mL}$ of $85 \%$ phosphoric acid to a volumetric flask and swirl. Transfer TCA solution into the volumetric flask and fill to the mark with water. Can be stored at $4^{\circ} \mathrm{C}$ for up to 6 weeks.

\section{TBA Reagent Solution:}

Weigh $2.883 \mathrm{~g}$ Thiobarbituric Acid (TBA) to a 1L volumetric flask. Add some deionized water to the flask and dissolve crystals in water. When crystals are dissolved, fill the flask to the $1 \mathrm{~L}$ mark. Prepare fresh daily.

TMP Solution:

Prepare a $20 \mathrm{mM}$ stock solution: dilute $0.335 \mathrm{~mL}$ TMP into $100 \mathrm{~mL}$ water (store up to 3 months at $\left.4^{\circ} \mathrm{C}\right)$. From the stock solution, transfer $1 \mathrm{~mL}$ to $100 \mathrm{~mL}$ water to get a working solution (store up to 1 month at $4^{\circ} \mathrm{C}$ ).

Procedure:

1. Homogenize $5 \mathrm{~g}$ of ground meat, $2.5 \mathrm{~mL}$ antioxidant solution and $50 \mathrm{~mL}$ TCA reagent for 2 minutes with a handheld blender.

2. Add $50 \mathrm{~mL}$ distilled water to the mixture and homogenize for an additional minute. 
3. Filter the slurry with a funnel lined with filter paper into a $100 \mathrm{~mL}$ volumetric flask.

4. Fill the flask to the mark with 1:1 TCA reagent/water.

5. Pipet a $5 \mathrm{~mL}$ aliquot into a $50 \mathrm{~mL}$ centrifuge tube.

6. Add $5 \mathrm{~mL}$ thiobarbituric acid (TBA) reagent to the solution; cap the tube and vortex for 3 seconds.

7. Place the tubes in a boiling water bath for 35 minutes, then place them promptly in ice for $5 \mathrm{~min}$.

8. Transfer the sample into a cuvette and read the absorbance at $532 \mathrm{~nm}$ using a spectrophotometer.

9. Zero the spectrophotometer with a reagent blank $(5 \mathrm{~mL} 1: 1 \mathrm{TCA}$ reagent/water and $5 \mathrm{~mL}$ TBA)

Standard Curve:

10. Transfer a series of aliquots $(0.5$ to $5 \mathrm{~mL})$ of $0.2 \mathrm{TMP}$ into 10 separate volumetric $100 \mathrm{~mL}$ flasks and fill each to the mark with 1:1 TCA reagent/water.

11. Pipet $5.0 \mathrm{~mL}$ aliquot from each volumetric flask into separate $50 \mathrm{~mL}$ centrifuge tubes and add 5mL TBA. Cap the tube and vortex for 3 seconds.

12. Place the tubes in a boiling water bath for 35 minutes, then place them promptly in ice for $5 \mathrm{~min}$.

13. Transfer the sample into a cuvette and read the absorbance at $532 \mathrm{~nm}$ using a spectrophotometer. 
14. Repeat steps 1-4 with new homogenized food samples, adding 1.5, 3.0 and 4.5 $\mathrm{mL}$ of $0.2 \mathrm{mM}$ TMP, respectively before step 2 . In step 2 , reduce the volume of distilled water accordingly. (Spiked samples)

15. Add $1.5,3.0$ and $4.5 \mathrm{~mL}$ of $0.2 \mathrm{mM}$ TMP to three separate $100 \mathrm{~mL}$ volumetric flasks and fill to the mark with 1:1 TCA reagent/water. (Diluted samples)

16. Perform the TBA reaction and measure absorbance (steps 5-9) using the three spiked and the three diluted samples.

17. Use the absorbance of the original (unspiked) food sample to correct for endogenous malonaldehyde content and then compare the spiked values to those in the TMP dilutions.

$\%$ recovery of TBARS $=100 \times \mathrm{A}_{\mathrm{sp}} / \mathrm{A}_{\mathrm{tmp}}$

$\mathrm{A}_{\mathrm{sp}}$ is the absorbance of the spiked food sample (corrected)

$\mathrm{A}_{\mathrm{tmp}}$ is the absorbance of the corresponding TMP dilution

The resulting percent recoveries are averaged and used in determining the TBA value.

Determining K (constant)

$\mathrm{K}=\left(\left((\mathrm{mol} \mathrm{MA} / 5 \mathrm{~mL}) / \mathrm{A}_{532}\right) \mathrm{x}(\mathrm{MA}\right.$ mol. weight $) \mathrm{x}(\mathrm{DF}) \mathrm{x}(106) \mathrm{x}(100 / \%$ recovery $\left.)\right) / \mathrm{m}$

- $(\mathrm{mol} \mathrm{MA} / 5 \mathrm{~mL}) / \mathrm{A}_{532}=1 /$ slope of the standard curve

- MA mol. weight $=72.03 \mathrm{~g} / \mathrm{mol}$

- $\mathrm{DF}=$ dilution factor $=5 \mathrm{~mL} / 100 \mathrm{~mL}$

- $\mathrm{M}=$ sample mass

TBA Value $=\mathrm{K} \times \mathrm{A}_{532}$

TBA Value $=\mathrm{mg}$ malonaldehyde $/ \mathrm{kg}$ sample 


\section{APPENDIX B: SAS CODES}

Fat content (covariate), TBARS (Thiobarbituric Acid Reactive Substances), Sensory Analysis, Oxymoglobin Content, and Minolta Chromameter L*, a* and b*.

options $1 \mathrm{~s}=100 \mathrm{ps}=70$;

data fat; infile 'e: Ifatn.csv' dsd firstobs=2 missover; input tag $\$$ co id fat;

*proc print;

$/ *$

proc mixed;

class tag co;

model fat $=\mathrm{co}$;

random tag;

lsmeans co/pdiff;

proc mixed;

class tag co;

model moi $=$ fat co;

random tag;

lsmeans co/pdiff;

*/

proc sort; by tag co;

data myoglobin; infile 'e:\myoglobinn.csv' dsd firstobs=2 missover;

input tag\$ co id CMYOD1A CMYOD3A CMYOD5A CMYOD7A;

*proc print;

proc sort; by tag co;

data minolta; infile 'e: $\backslash$ minoltan.csv' dsd firstobs=2 missover;

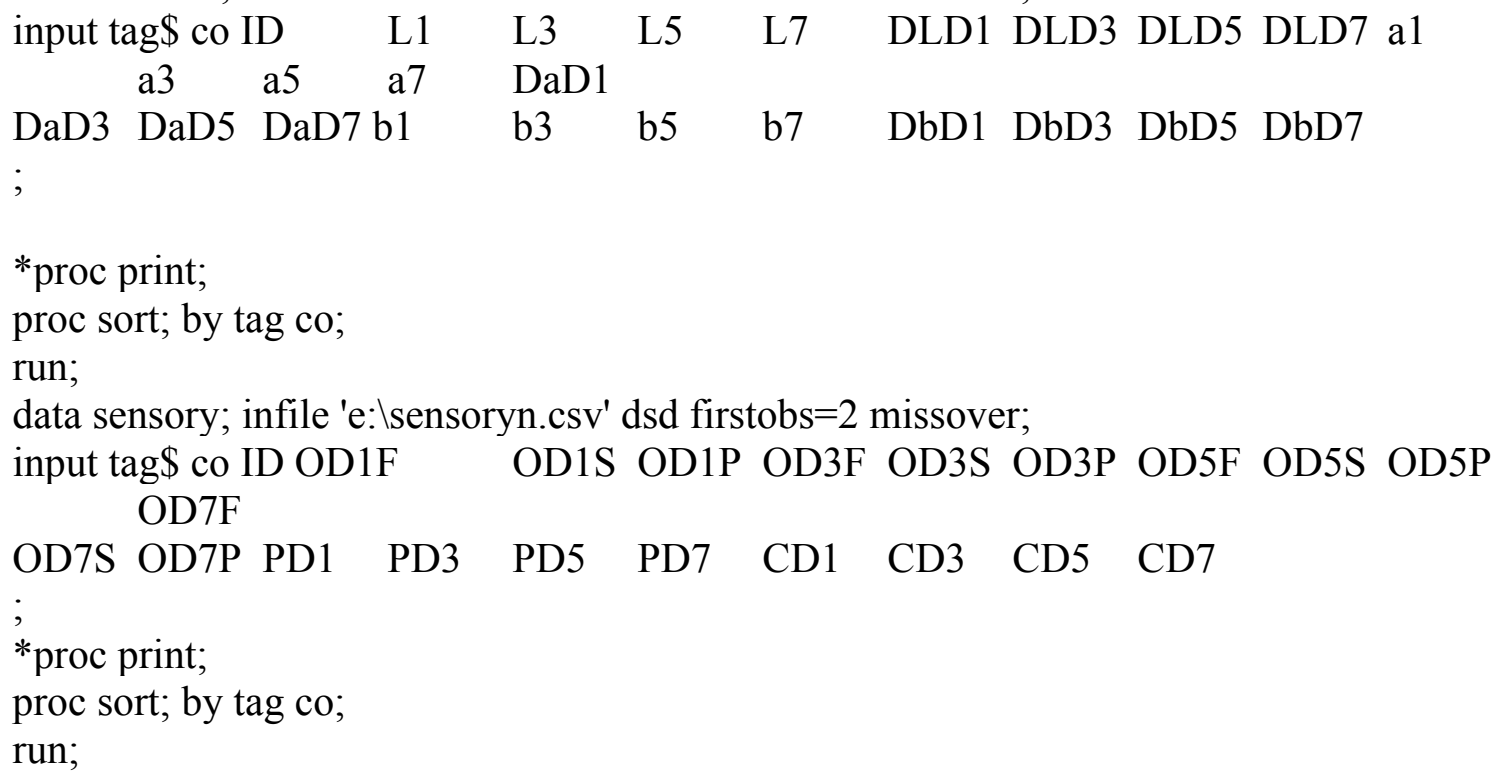


data tbars; infile 'e: tbarsf.csv' dsd firstobs $=2$ missover;

input TAG\$ CO ID D2TBAA D6TBAA;

proc sort; by tag co;

run;

*proc print;

data all; merge fat myoglobin minolta sensory tbars; by tag co;

*proc print;

/*proc mixed;

class tag co;

model fat $=\mathrm{co}$;

random tag;

lsmeans co/pdiff;

proc mixed;

class tag co;

model CMYOD1A = fat co;

random tag;

lsmeans co/pdiff;

proc mixed;

class tag co;

model CMYOD3A = fat co;

random tag;

lsmeans co/pdiff;

proc mixed;

class tag co;

model CMYOD5A = fat co;

random tag;

lsmeans co/pdiff;

proc mixed;

class tag co;

model PD1 = fat co;

random tag;

1smeans co/pdiff;

proc mixed;

class tag co;

model PD3 = fat co;

random tag;

lsmeans co/pdiff;

proc mixed; 


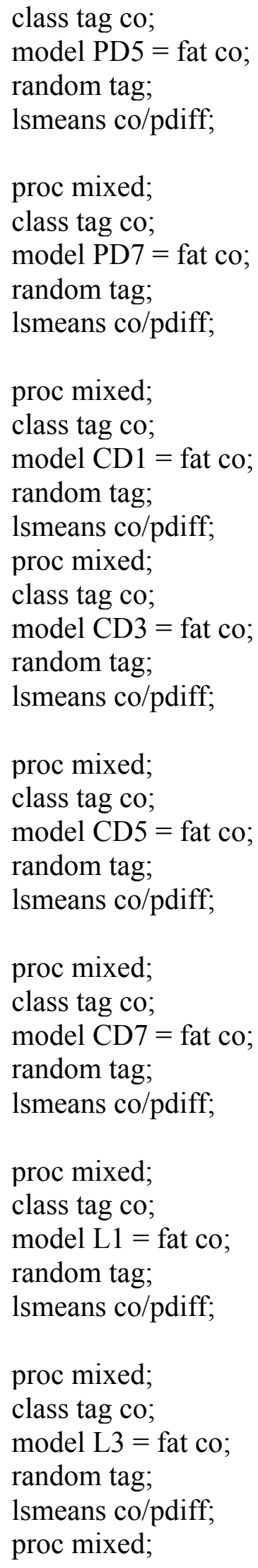




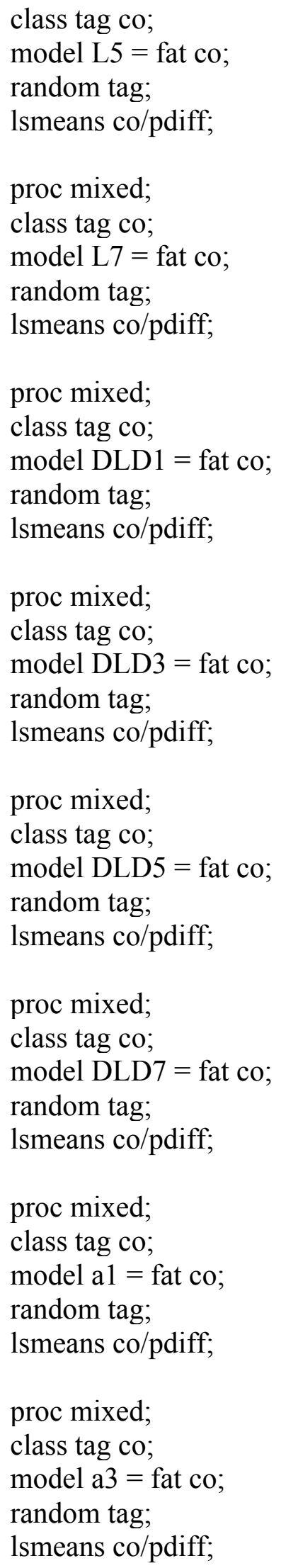


proc mixed;

class tag co;

model a5 = fat co;

random tag;

1smeans co/pdiff;

proc mixed;

class tag co;

model a7 = fat co;

random tag;

lsmeans co/pdiff;

proc mixed;

class tag co;

model dad 1 = fat co;

random tag;

lsmeans co/pdiff;

proc mixed;

class tag co;

model dad3 = fat co;

random tag;

lsmeans co/pdiff;

proc mixed;

class tag co;

model dad5 = fat co;

random tag;

lsmeans co/pdiff;

proc mixed;

class tag co;

model dad7 = fat co;

random tag;

lsmeans co/pdiff;

proc mixed;

class tag co;

model b1 = fat co;

random tag;

lsmeans co/pdiff;

proc mixed;

class tag co;

model b3 = fat co; 
random tag;

lsmeans co/pdiff;

proc mixed;

class tag co;

model b5 = fat co;

random tag;

lsmeans co/pdiff;

proc mixed;

class tag co;

model b7 = fat co;

random tag;

lsmeans co/pdiff;

proc mixed;

class tag co;

model dbd1 = fat co;

random tag;

lsmeans co/pdiff;

proc mixed;

class tag co;

model dbd3 = fat co;

random tag;

lsmeans co/pdiff;

proc mixed;

class tag co;

model dbd5 = fat co;

random tag;

lsmeans co/pdiff;

proc mixed;

class tag co;

model dbd7 = fat co;

random tag;

lsmeans co/pdiff;

proc mixed;

class tag co;

model CMYOD7A = fat co;

random tag;

lsmeans co/pdiff;

run;

*/ 
proc mixed;

class tag co;

model OD1F = fat co;

random tag;

lsmeans co/pdiff;

proc mixed;

class tag co;

model OD1S = fat co;

random tag;

lsmeans co/pdiff;

proc mixed;

class tag co;

model OD1P = fat co;

random tag;

lsmeans co/pdiff;

proc mixed;

class tag co;

model OD3F = fat co;

random tag;

lsmeans co/pdiff;

proc mixed;

class tag co;

model OD3S = fat co;

random tag;

lsmeans co/pdiff;

proc mixed;

class tag co;

model OD3P = fat co;

random tag;

lsmeans co/pdiff;

proc mixed;

class tag co;

model OD5F = fat co;

random tag;

lsmeans co/pdiff;

proc mixed;

class tag co;

model OD5S = fat co; 
random tag;

1smeans co/pdiff;

proc mixed;

class tag co;

model OD5P = fat co;

random tag;

lsmeans co/pdiff;

proc mixed;

class tag co;

model OD7F = fat co;

random tag;

lsmeans co/pdiff;

proc mixed;

class tag co;

model OD7S = fat co;

random tag;

lsmeans co/pdiff;

proc mixed;

class tag co;

model OD7P = fat co;

random tag;

lsmeans co/pdiff;

proc mixed;

class tag co;

model D2TBAA = fat co;

random tag;

lsmeans co/pdiff;

proc mixed;

class tag co;

model D6TBAA = fat co;

random tag;

lsmeans co/pdiff;

Flavor Volatiles and Fat content (covariate).

options $1 \mathrm{~s}=100 \mathrm{ps}=70$;

data fat; infile 'e: $14172013 \backslash$ fatn.csv' dsd firstobs $=2$ missover;

input tag $\$$ co id fat;

*proc print; 


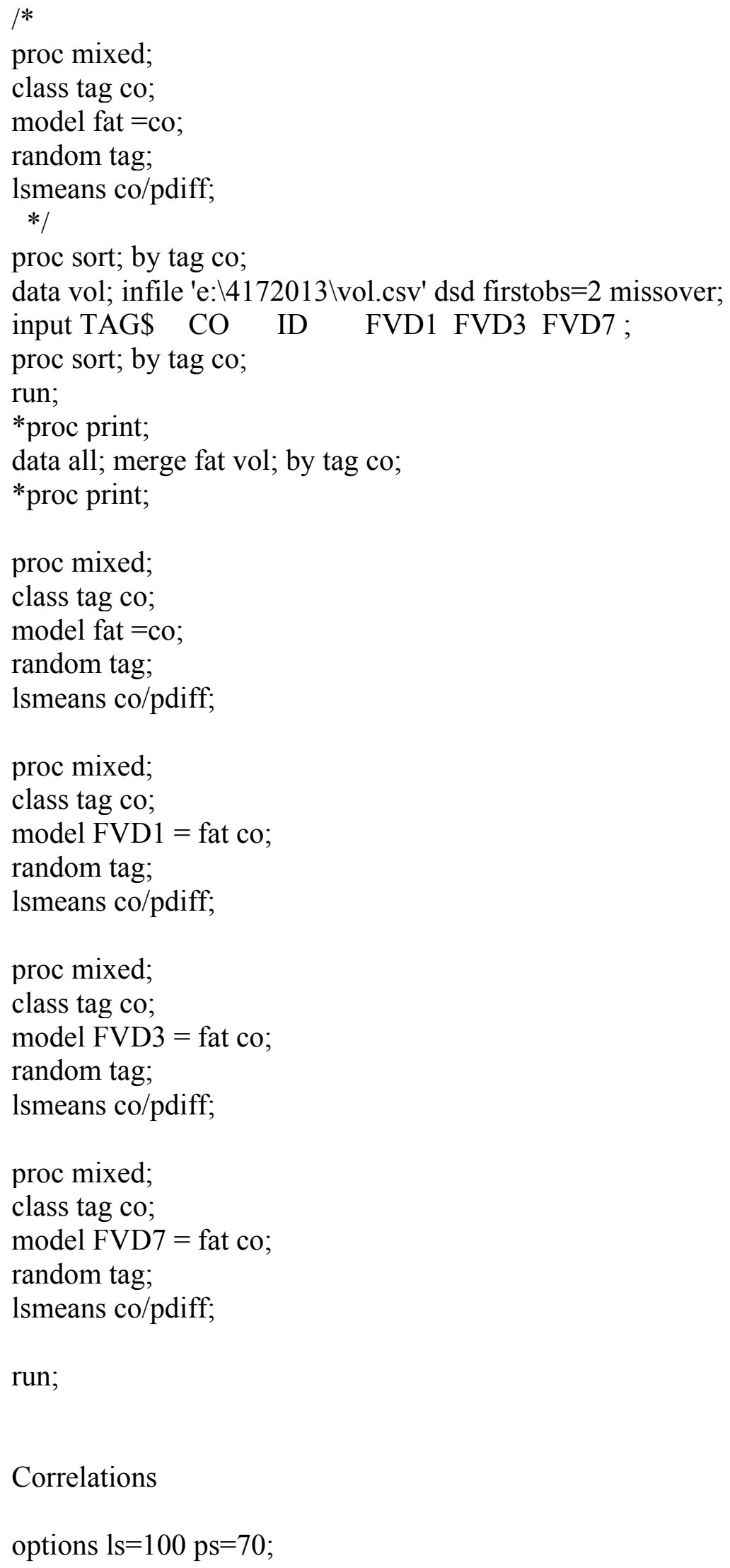


data fat; infile 'e: $\backslash S A S \backslash 4172013 \backslash$ fatn.csv' dsd firstobs=2 missover;

input tag\$ co id fat moi;

*proc print;

/*

proc mixed;

class tag co;

model fat $=\mathrm{co}$;

random tag;

lsmeans co/pdiff;

proc mixed;

class tag co;

model moi $=$ fat co;

random tag;

lsmeans co/pdiff;

*/

proc sort; by tag co;

data myoglobin; infile 'e: $\mid \mathrm{SAS} \backslash$ myoglobinn.csv' dsd firstobs=2 missover; input tag\$ co id CMYOD1A CMYOD3A CMYOD5A CMYOD7A;

*proc print;

proc sort; by tag co;

data minolta; infile 'e: $\backslash S A S \backslash$ minoltan.csv' dsd firstobs=2 missover;

input tag\$ co Code L1 L3 L5 L7 DLD1 DLD3 DLD5 DLD7 a1

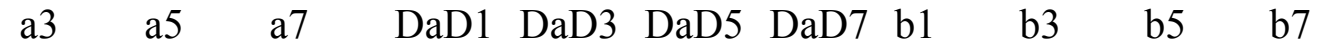

DbD1 DbD3 DbD5 DbD7

;

*proc print;

proc sort; by tag co;

run;

data sensory; infile 'e: $\backslash \mathrm{SAS} \backslash 4172013 \backslash$ sensoryn.csv' dsd firstobs=2 missover;

input tag\$ co code OD1F OD1S OD1P OD3F OD3S OD3P OD5F OD5S OD5P

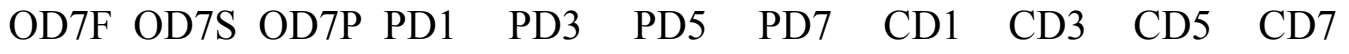

;

*proc print;

proc sort; by tag co;

data fvol; infile 'e: $\backslash S A S \backslash 4172013 \backslash$ vol.csv' dsd firstobs=2 missover;

input TAG\$ CO ID FVD1 FVD3 FVD7

;

proc print;

proc sort; by tag co;

data tbars; infile 'e: $\backslash S A S \backslash 4172013 \backslash$ tbarsf.csv' dsd firstobs=2 missover;

input TAG\$ CO ID D2TBAA D6TBAA

;

proc print; 
proc sort; by tag co;

run;

data all; merge fat myoglobin minolta sensory fvol tbars; by tag co;

*proc print;

proc sort; by co;

proc corr;

var CMYOD1A CMYOD3A CMYOD5A CMYOD7A a1 a3 a5 a7

DaD1 DaD3 DaD5 DaD7 b1 b3 b5 b7 $\mathrm{DbD} 7$

PD1 PD3 PD5 PD7 CD1 CD3 CD5 CD7 OD1F OD1S OD1P OD3F OD3S OD3P OD5F OD5S OD5P OD7F OD7S OD7P

D2TBAA D6TBAA FVD1 FVD3 FVD7;

run; 